Boletín de la Sociedad Geológica Mexicana

Volumen 61, NÚM. 3, 2008, P. 305-324

\title{
Criterios ambientales y geológicos básicos para la propuesta de un relleno sanitario en Zinapécuaro, Michoacán, México
}

\author{
Juan Manuel Sánchez-Núñez ${ }^{1, *}$, Jessica Velázquez Serna², Ma. Elena Serrano Flores ${ }^{1}$, \\ Alfredo Ramírez Treviño ${ }^{3}$, Alejandro Balcazar Vázquez ${ }^{1}$, Raúl Quintero Rodríguez ${ }^{4}$ \\ ${ }^{1}$ Centro Interdisciplinario de Investigaciones y Estudios sobre Medio Ambiente y Desarrollo (CIIEMAD) del Instituto Politécnico \\ Nacional. Calle 30 de junio de 1520, Col. Barrio la Laguna Ticomán. Delegación Gustavo A. Madero. \\ C. P. 07340, México D. F. \\ ${ }^{2}$ Escuela Nacional de Ciencias Biológicas. Ingeniería en Sistemas Ambientales del Instituto Politécnico Nacional, \\ Prolongación de Carpio y Plan de Ayala, Col. Santo Tomás. Delegación Miguel Hidalgo. \\ C.P. 11340 México, D.F. \\ ${ }^{3}$ Escuela Superior de Ingeniería Mecánica y Eléctrica del Instituto Politécnico Nacional, Unidad Azcapotzalco. \\ Av. de las Granjas No. 682 Col. Sta. Catarina Delegación Azcapotzalco. C. P. 02550 México D.F. \\ ${ }^{4}$ Proyectos de Ingeniería y Medio Ambiente (PIMA). Jesús Flores 33-2 Col. Observatorio. \\ Delegación Miguel Hidalgo. C.P. 11860 México, D.F. \\ *jmsanchezn2004@yahoo.com.mx
}

\section{Resumen}

El municipio de Zinapécuaro ubicado a $50 \mathrm{~km}$ de la ciudad de Morelia, Michoacán no esta exento de los problemas de la disposición de los Residuos Sólidos Urbanos generados por sus 14547 habitantes; actualmente dichos residuos se depositan en un área que no cuenta con las especificaciones técnicas de un sitio de disposición, lo que genera alteraciones al medio como son: contaminación visual y del suelo, malos olores, generación de fauna nociva y degradación del recurso hídrico, entre los más significativos. La disposición inadecuada de los residuos en el municipio de Zinapécuaro es un problema vigente que debe ser tratado con urgencia. Por lo anterior, el objetivo central del presente estudio se enfocó a realizar una propuesta técnica básica, donde se señalan los elementos para la selección del sitio y los principios de diseño para la construcción de un relleno sanitario.

Los trabajos de investigación se basaron en la Norma Oficial Mexicana NOM 083-SEMARNAT-2003 y las Normas Técnicas Mexicanas (NMX) que marcan los lineamientos para la caracterización de los residuos generados en una comunidad. Como resultado de la aplicación de dichas normas, se determinó que, la categoría del sitio de disposición final es tipo "C"; que la densidad de población del municipio para el año 2000 fue de 94 habitantes por $\mathrm{km}^{2}$, lo que se traduce en un incremento en la generación per cápita de residuos y que con base en el análisis estadístico realizado al muestreo de los residuos sólidos, se determinó que la generación promedio es de $0.62 \mathrm{~kg} / \mathrm{hab} /$ día y su peso volumétrico es de $252.54 \mathrm{~kg} / \mathrm{m}^{3}$.

Se identificaron cuatro unidades litológicas: rocas basálticas y depósitos volcanoclásticos del Terciario Superior y Cuaternario; así como depósitos lacustres y aluviales del Cuaternario que coronan la secuencia litológica.

Es importante remarcar que las autoridades del municipio mostraron interés en aprovechar estructuras abandonadas de minas a cielo abierto donde eran explotados materiales pétreos para la construcción. Por lo anterior, el sitio Francisco Villa cumplió con las especificaciones técnicas que marca la normatividad para un sitio tipo $\mathrm{C}$, aunque resultaría conveniente realizar otros estudios de mayor detalle para complementar la presente propuesta.

Palabras clave: Relleno sanitario, residuos sólidos urbanos, legislación ambiental, Norma Oficial Mexicana, geología.

\begin{abstract}
Zinapécuaro is located $50 \mathrm{~km}$ of Morelia, capital city of the state of Michoacan, this region has several problems because of domestic solid waste generated by 14547 people; the actual disposal dump does not have any technical specifications, so it has environmental implications like soil, air and water pollution as well as unpleasant odors, harmful animals and groundwater resources pollution. The
\end{abstract}


final disposition of solid waste in Zinapecuaro is one of the most critical and imperative problems to be solved. This study deals with basic technical proposal to establish the bases to select the suitable place for building a landfill according to the actual environmental regulation. The main criteria followed by this research were the Norma Oficial Mexicana NOM 083-SEMARNAT-2003 and four Mexican Technical Standards (NMX) that contain the procedures to determine the type of materials generated. According to statistical analysis applied to domestic solid waste sampling, the final disposition site at Zinapecuaro is classified as " $C$ " type, the generation average is 0.62 kilograms per inhabitant per each day and the volumetric weight is $252.54 \mathrm{~kg} / \mathrm{m}^{3}$. The kinds of rocks identify were basalts and volcanoclastic deposits range from Superior Triasic to Quaternary. Also presented lacustrine deposits and the most recent alluvial sediments are at the top of the stratigraphic column. The municipal authorities were interested in abandoned mine use for landfill, so Francisco Villa site fulfilled technical specifications for " $C$ " type of disposal dump. We strongly recommend some specific studies as a compliment to this research.

Key words: Sanitary landfill, domestic solid waste, environmental regulations, Norma Oficial Mexicana, Geology.

\section{Introducción}

Los Residuos Sólidos Urbanos (RSU) son materiales que provienen de las actividades humanas de transformación y consumo, que no representan una utilidad o un valor económico para el poseedor y que al desecharlos éste se convierte en un generador. Los residuos se pueden clasificar tanto por su estado físico, su origen (domésticos o industriales) o bien por sus características fisicoquímicas (Durán de la Fuente, 1997). En el primer caso se distinguen tres tipos: sólidos, líquidos y gaseosos; sin embargo, esta clasificación puede verse limitada por tratarse de una clasificación puramente descriptiva, además que en ningún momento se consideran las características de peligrosidad de dichos residuos (Tchobanoglous, 1998).

La disposición final de los residuos sólidos, es la última etapa del proceso que siguen éstos a partir de su generación (Seoánez, 1993). Durante varias décadas, esta actividad no representó un problema serio, ya que bastaba con llevar los residuos sólidos fuera de los núcleos urbanos para evitar el impacto visual negativo y las molestias que podían ocasionar a la población. Además, la cantidad en que eran producidos y las características en cuanto a su composición, permitían que éstos se reintegraran rápidamente al ciclo natural sin ocasionar daños significativos al medio (Orta, 2004).

A partir de los años cuarenta, en nuestro país, se incrementa sustancialmente la generación de los residuos sólidos y las características de éstos se ven modificadas. Lo anterior se da como resultado del desarrollo tecnológico, la introducción de nuevos productos y de la explosión demográfica; todo ello ha creado lo que Henry y Heinke, 1999 han llamado la sociedad "desechable".

Ante estos cambios y frente a la persistencia de prácticas tradicionales en la disposición de los residuos sólidos, evidentemente aparecen numerosos tiraderos a cielo abierto, los cuales constituyen un foco de contaminación para el agua, aire y suelo, así como un medio adecuado para el desarrollo de fauna nociva que pueden constituir vectores de peligro para la salud de la población; todo ello sin olvidar el deterioro de la imagen del lugar (Robles, 2005). Aunado a lo anterior, cabe señalar que la presencia de diversos materiales integrados en los residuos sólidos y depositados en dichos tiraderos, ha provocado el auge de la actividad conocida como "pepena", que se efectúa en condiciones inadecuadas, ocasionando con esto un problema de marginación social, así como de salud para las propias familias que llevan a cabo esta práctica.

México, al igual que muchos países del mundo, enfrenta grandes retos en el manejo de sus RSU. En casi 50 años la población nacional se ha triplicado, pasando de 30 millones en la década de los años cincuenta a más de 97 millones en 1997. En el mismo período, la generación per cápita nacional de residuos pasó de 300 a 850 gramos por habitante al día, debido principalmente al cambio de hábitos de consumo. Para 1997 se estimó una generación de 82,600 ton/día de residuos sólidos, de la cual, sólo el 77\% era recolectado (63,600 ton/día) y sólo el 35\% (28,900 ton/ día) se depositaba en sitios controlados (rellenos sanitarios y tiraderos controlados), quedando 53,700 ton/día en tiraderos a cielo abierto (INE-SEMARNAT, 2001).

Es evidente que la disposición de residuos en tiraderos abiertos se ha convertido en un problema ambiental que necesita ser resuelto (Israde-Alcántara et al., 2005). Por lo anterior, el gobierno mexicano, a través de las diferentes instancias de gobierno: federal, estatal y municipal, ha planteado la necesidad urgente de enfrentar el problema de la disposición final de los residuos sólidos urbanos a corto plazo. Para ello, ha considerado conveniente establecer los criterios y lineamientos suficientes (Norma Oficial Mexicana NOM-083-SEMARNAT-2003) para contar con los elementos técnicos suficientes y lograr la disposición, clausura y saneamiento ambiental de los sitios destinados para este fin; todo ello con el objetivo de mejorar las condiciones ecológicas de los medios circundantes, además de prevenir y controlar los impactos negativos que afectan al ambiente y a la salud de la población.

Respecto a los estudios regionales previos, y que son un referente, destacan las investigaciones de Buenrostro e Israde-Alcántara, 2003, Israde-Alcántara et al., 2004, Santiago, 2005 y Flores-Flores, 2005. En éstos se trata el problema de contaminación producida por los tiraderos a 

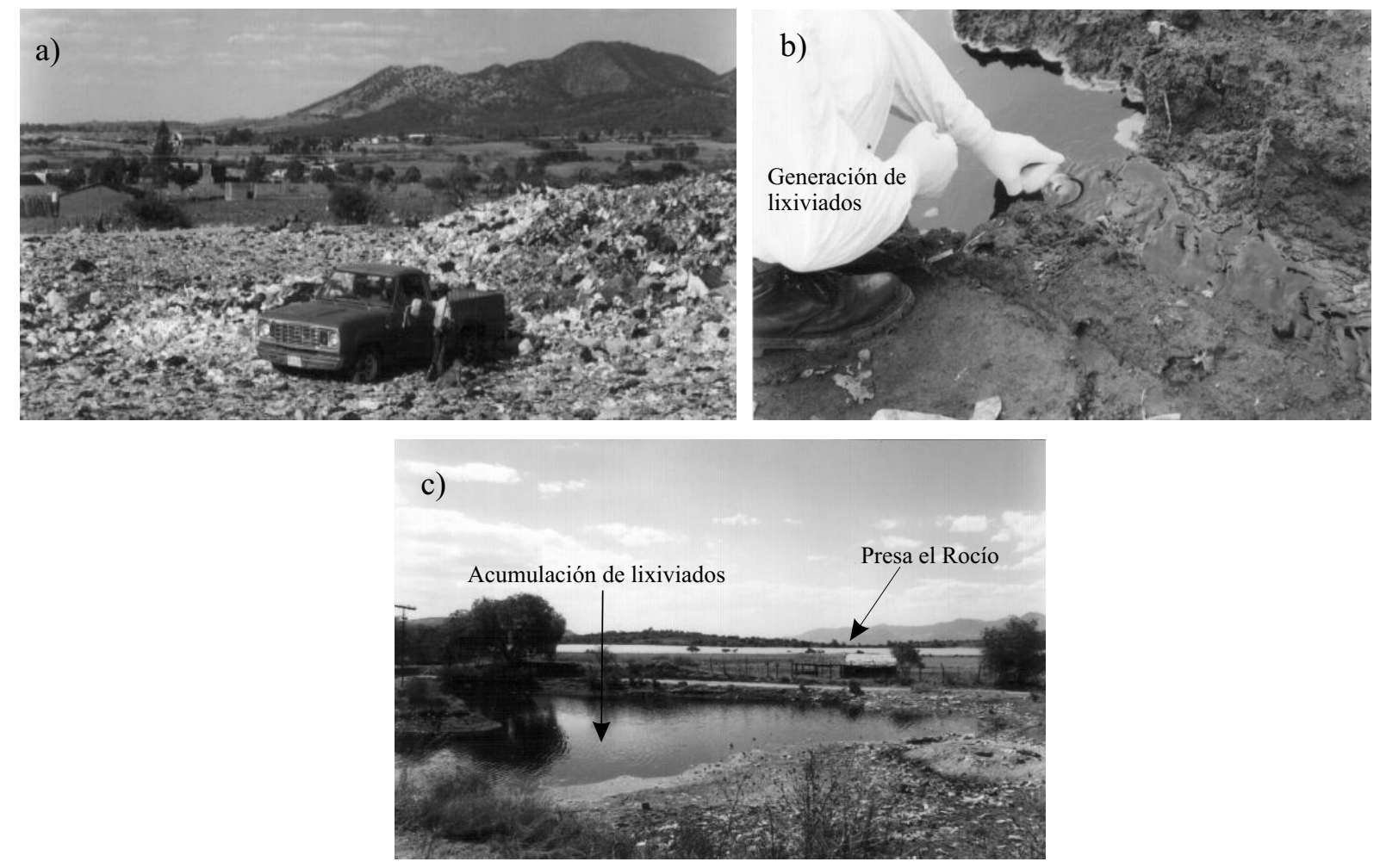

Figura 1. Problemas ambientales generados por el tiradero en Zinapécuaro, Michoacán. a) Vista parcial del tiradero, donde se observa que no existe cobertura de los residuos, lo que genera vectores de enfermedad. b) Generación de lixiviados potencialmente contaminantes con metales pesados que pueden ser altamente tóxicos. c) En primer plano, se muestra la acumulación de lixiviados y en segundo plano aparece la Presa el Rocío. En temporada de lluvias ambos cuerpos llegan a juntarse, provocando daños a este cuerpo de agua superficial.

cielo abierto y el impacto negativo producido a los cuerpos de agua superficiales y subterráneos. Abordan también las alteraciones provocadas por los lixiviados que escurren o se infiltran, modificando la calidad de los suelos y los recursos hídricos, tanto superficiales como subterráneos.

En México, son pocos los estudios sobre lixiviados provenientes de tiraderos municipales, en especial de la región de Michoacán. En el estudio realizado por IsradeAlcántara et al., 2004 sobre la caracterización del tiradero de la ciudad de Morelia se señala que dicho tiradero opera desde 1984, que no existe control de lixiviados y biogases y que la permeabilidad de las rocas donde se localiza el tiradero, son de alta porosidad y permeabilidad. Además, se menciona que en este tiradero se utilizan arenas volcánicas y tobas como cubierta de los residuos, situación que contrasta con el caso de estudio que se aborda en este documento, pues en éste, no se utiliza ninguna cubierta, sino después de varios meses de vertido de residuos (Figura 1a).

La problemática ambiental que enfrenta Zinapécuaro ${ }^{1}$, no es privativa de esta comunidad, sino de todos los municipios que se localizan en la parte alta de la cuenca del lago de Cuitzeo, donde se vierten grandes cantidades de resi-

${ }^{1}$ Cuando se menciona Zinapécuaro, en este trabajo se refiere a la Cabecera Municipal y no al Municipio. duos sólidos residenciales e industriales, llegando a afectar ciudades tan importantes como Morelia (González, 2003 y Santiago-Hipólito, 2005); Al igual que otras ciudades michoacanas, Zinapécuaro ha experimentado una rápida expansión urbana, en ocasiones provocada por fenómenos naturales como el sismo de 1985 (Arreygue-Rocha et al., 2001). Otro argumento importante del problema de los residuos sólidos en la cuenca, es que existen serios problemas de organización, administración y planeación (IsradeAlcantara et al., 2004 y Buenrostro e Israde-Alcantara , 2002 y 2003).

De acuerdo con Santiago-Hipólito, 2005; FloresFlores, 2005 y Sánchez-Nuñez et al., 2007; en el tiradero de Zinapécuaro no existe control en el manejo y disposición de los RSU generados por sus casi 15,000 habitantes. El lugar de depósito de residuos no cuenta con especificaciones técnicas de un sitio de disposición final por lo que se generan alteraciones al ambiente como son: emisiones a la atmósfera de Metano y $\mathrm{CO}_{2}$ principalmente, malos olores, contaminación del suelo y subsuelo. Estos tres estudios abordaron de manera importante la determinación de los contaminantes presentes en los lixiviados provenientes del tiradero de RSU, enfatizando los metales pesados $(\mathrm{Hg}$, $\mathrm{Pb}, \mathrm{As}, \mathrm{Cd}, \mathrm{Cr}$, Ni y $\mathrm{Cu}$ ) que son potencialmente tóxicos al medio ambiente y que constituyen un peligro para los habitantes de la región. Estos estudios coinciden en las al- 
tas concentraciones de dichos metales en sedimentos y sus bajos valores en la fase líquida (Figura 1b).

El tiradero de Zinapécuaro propicia contaminación visual, generación de fauna nociva y motiva también que los residuos sean arrojados en el río Zinapécuaro y en el arrollo "La Barranquilla" (Vargas, 2000).

Como un rasgo notable en la generación de residuos en Zinapécuaro es la abundancia del PET, esto debido a que la entidad cuenta con aguas termales y azufradas, lo que hizo posible la construcción de balnearios, los que en fines de semana, días festivos y vacacionales son visitados por turistas (población flotante) que generan grandes cantidades de este residuo al consumir bebidas embotelladas.

El estudio se hace necesario debido a que el tiradero actual, está rodeado por áreas de cultivo, zonas de pastoreo y se encuentra cerca de un cuerpo de agua superficial (presa el Rocío), que es utilizado como abrevadero y fuente de irrigación (Figura 1c). Los lugareños señalan que en la presa se practicaba la pesca, pero que los peces han muerto y que las personas que tienen contacto con el agua pueden sufrir irritación de la piel. Resulta evidente que el vertedero de residuos constituye un problema que debe ser tratado con urgencia, por lo anterior, se plantea como objetivo principal de este estudio: Proponer un sitio para la disposición final de RSU, que cuente con las especificaciones técnicas señaladas en la normatividad ambiental vigente, además de establecer los criterios geológicos que coadyuven con el problema de la disposición inadecuada de residuos sólidos urbanos en Zinapécuaro, Michoacán; que es el tiradero que recibe mayor cantidad de RSU de los localizados dentro de la cuenca del lago de Cuitzeo (Santiago-Hipólito, 2005). De este modo, existirá la posibilidad de sanear el tiradero actual y restaurar las afectaciones provocadas al medio ambiente en sus 20 años que tiene de funcionamiento.

\section{Metodología}

En la primera etapa de la investigación se recopiló, clasificó y sistematizó información sobre la problemática ambiental relativa a los RSU y las diferentes alternativas que existen para su control, minimización y disposición final, con el objetivo de sustentar el hecho de que un relleno sanitario pueda ser una alternativa viable. Se consideraron los criterios más recientes en cuanto a normatividad ambiental se refiere, con el fin de contar con las herramientas necesarias para elaborar una propuesta ambientalmente sustentable.

Para la descripción del medio físico de Zinapécuaro, se realizó un trabajo intensivo de campo, en el que se reconocieron las unidades litológicas, los diferentes tipos de suelo y la descripción hidrológica, lo anterior por considerarse parte fundamental en la evaluación geológica para este tipo de estudios (Brunner y Keller, 1972).

No debe perderse de vista que los requisitos que señala la normatividad ambiental para sitios de disposición final clasificados como Tipo "C" son menos cuando se les compara con los sitios clasificados como tipo "A". Sin embargo, un criterio común para todos los tipos es la realización del estudio de generación de residuos sólidos, para lo cual se siguieron los lineamientos marcados por la Norma Mexicana NMX-AA-061-1985 (Figura 2).

Para el muestreo de residuos, se utilizó como referencia la Norma Mexicana NMX-AA-015-1985 que establece el método de cuarteo para residuos sólidos urbanos y la Norma Mexicana NMX-AA-019-1985, que establece el método para determinar el peso volumétrico de los residuos sólidos; de igual modo, se utilizó la Norma Mexicana NMX-AA-022-1985 que establece la selección y el método para la cuantificación de subproductos contenidos en los RSU. La Figura 3 sintetiza el proceso seguido en la determinación de los diferentes parámetros para la propuesta del relleno sanitario.

\section{Caracterización geológica del área de estudio}

Desde un punto de vista regional, el sitio de estudio se localiza al noreste del estado de Michoacán (Figura 4) y está enclavado en el municipio de Zinapécuaro de Figueroa (CRM, 1995). La posición geográfica del lugar propuesto para la construcción del relleno sanitario son las coordenadas $19^{\circ} 52.6^{\prime}$ de Latitud Norte y $100^{\circ} 55.6^{\prime}$ de Longitud Oeste, a una altitud de $1952 \mathrm{msnm}$. Esta región ocupa $3527 \mathrm{~km}^{2}$ y absorbe el $20.7 \%$ de la población total del Estado. De acuerdo con García (1973) El clima que predomina es el templado $(\mathrm{C})$ que se caracteriza porque sus temperaturas medias anuales son de $18^{\circ} \mathrm{C}$ en los valles y hasta los $12.5^{\circ} \mathrm{C}$ en las serranías.

La caracterización que a continuación se presenta no es solo una recopilación de datos aislada, sino que en ésta se fundamenta el diseño y la propuesta técnica del relleno sanitario, la cual nunca debe presentarse en forma separada del elemento social, que finalmente, es el sector directamente beneficiado o afectado con dichas acciones.

De los estudios realizados por Arreygue-Rocha et al., 2001 y Ferrari et al., 1994 en la región de la Ciudad de Morelia, se puede establecer que en la zona de estudio se manifiestan dos provincias geológicas importantes, la Sierra Madre Occidental y el vulcanismo y tectonismo del Cinturón Volcánico Mexicano, caracterizándose por la presencia de actividad sísmica y volcánica asociada a estructuras de carácter regional. En esta segunda provincia se presenta el dominio de edificios volcánicos con elevaciones que alcanzan los 3800 m (López, 1983). Geomorfológicamente el área de estudio se caracteriza por la presencia de numerosos conos de origen volcánico con altitudes que alcanzan los $3000 \mathrm{msnm}$, teniendo como nivel mas bajo la Laguna de Yuriria y el Lago de Cuitzeo, cuyo nivel de sus aguas oscila alrededor de los 1,700 m. snm (CNA, 2002).

Otro rasgo importante que se presenta al oriente de la 


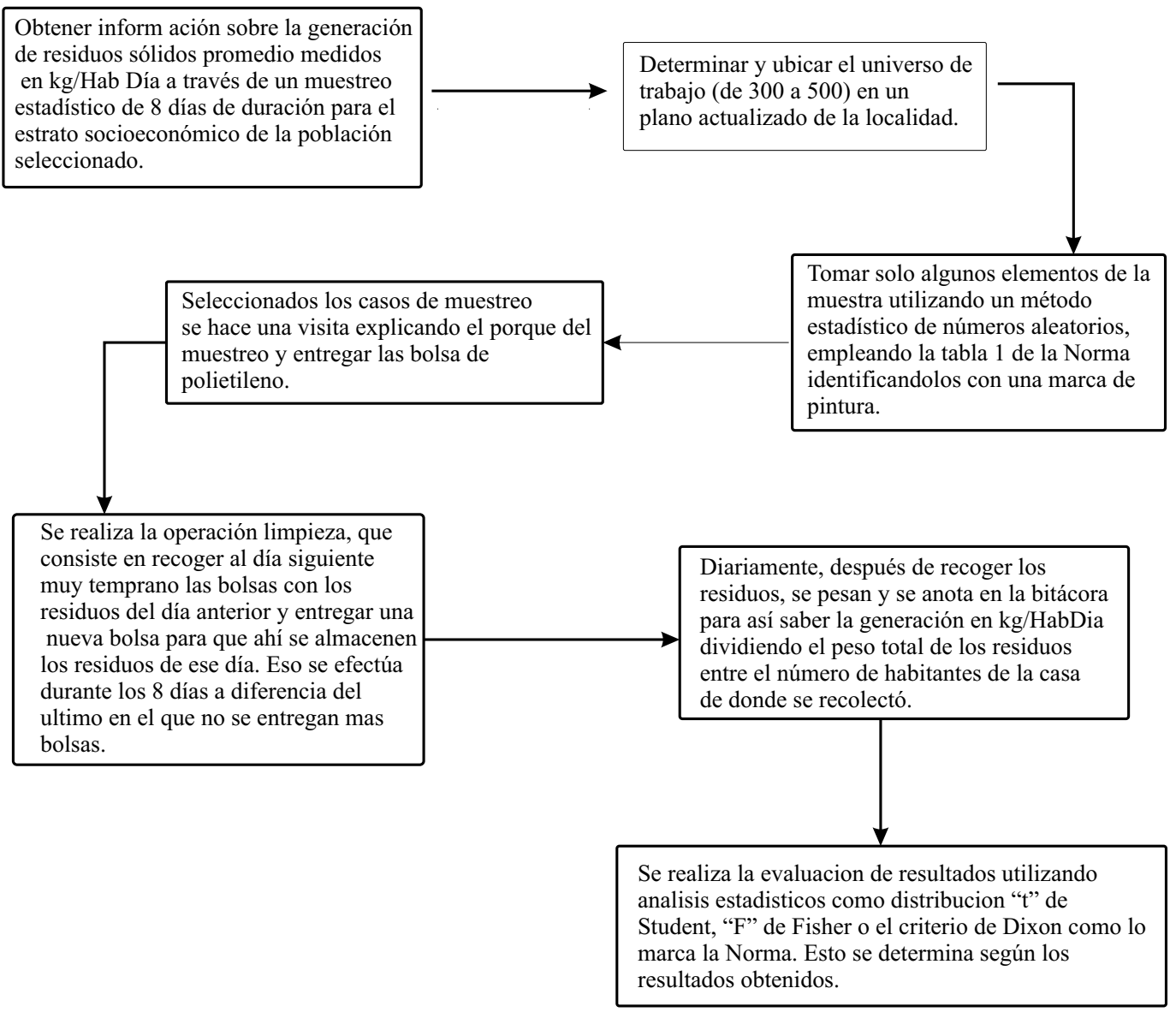

Figura 2. Metodología para el estudio de generación de residuos sólidos urbanos.

cabecera municipal de Zinapécuaro es la presencia de volcanes monogenéticos y conos de lavas pertenecientes al campo volcánico Michoacán-Guanajuato que cubren a secuencias lacustres del Mioceno-Plioceno (Israde-Alcantara y Garduño-Monroy, 1999; Hasenaka y Carmichael, 1985). También presenta rasgos particulares como son las llanuras aluviales y lacustres, características morfológicas que se hacen presentes en la zona estudiada, muestra de ello es el lago de Cuitzeo localizado al Norte y al NW de la cabecera municipal.

Localmente, la topografía plana presente en la porción occidental de la cabecera municipal de Zinapécuaro contrasta con la porción oriental, aquí se manifiestan estructuras topográficas con elevaciones que van de los 1900 hasta los $2800 \mathrm{msnm}$, algunos ejemplos de estas estructuras son las que se conocen localmente como: cerro Mozo, Monterrey, El Barco, Las Rosas, El Pedrillo, El Piojo y Clavelinas; estos tres últimos localizados al suroeste de la cabecera municipal. También se localizan estructuras de cima plana (mesas), como Lucas, Pilada, Coralera, El Palillo y Cerro de San Martín.

De acuerdo con la CNA (2002), los rasgos estructurales más importantes son dos sistemas de fallas, el que sigue un arreglo ENE-WSW; representado por el sistema de fallas normales y que algunos autores denominan sistema de fallas de Cuitzeo y el otro sistema es el asociado al río Lerma, que presenta una dirección NW-SE. Localmente, se manifiestan fallas, en su mayoría normales que pertenecen al primer sistema, sus dimensiones van desde los $2 \mathrm{~km}$ hasta estructuras regionales de $15 \mathrm{~km}$ de longitud.

Las características litológicas del estado de Michoacán han sido descritas por diferentes autores, siendo uno de los primeros el trabajo de Santiago Ramírez en 1872. En 1888 el Instituto Geológico realizó una cartografía detallada del Estado y no es sino hasta 1900 - 1901 cuando los geólogos Aguilera y Ordóñez reconocen con detalle las rocas volcánicas del Terciario Superior y Cuaternario del noreste del Estado; justamente donde se localiza el área de estudio (CRM, 1995).

En 1995 el Consejo de Recursos Minerales generó información detallada de la geología de Michoacán, de esta se puede observar que aproximadamente en el $40 \%$ del territorio michoacano (centro y noroeste) afloran rocas basálticas cuaternarias, hacia el suroeste predominan rocas cretácicas de tipo volcánico, volcanosedimentarias y marinas, mientras que, rocas volcánicas ácidas del Terciario y el Cuaternario, cubren casi de toda la región oriental del Estado. 


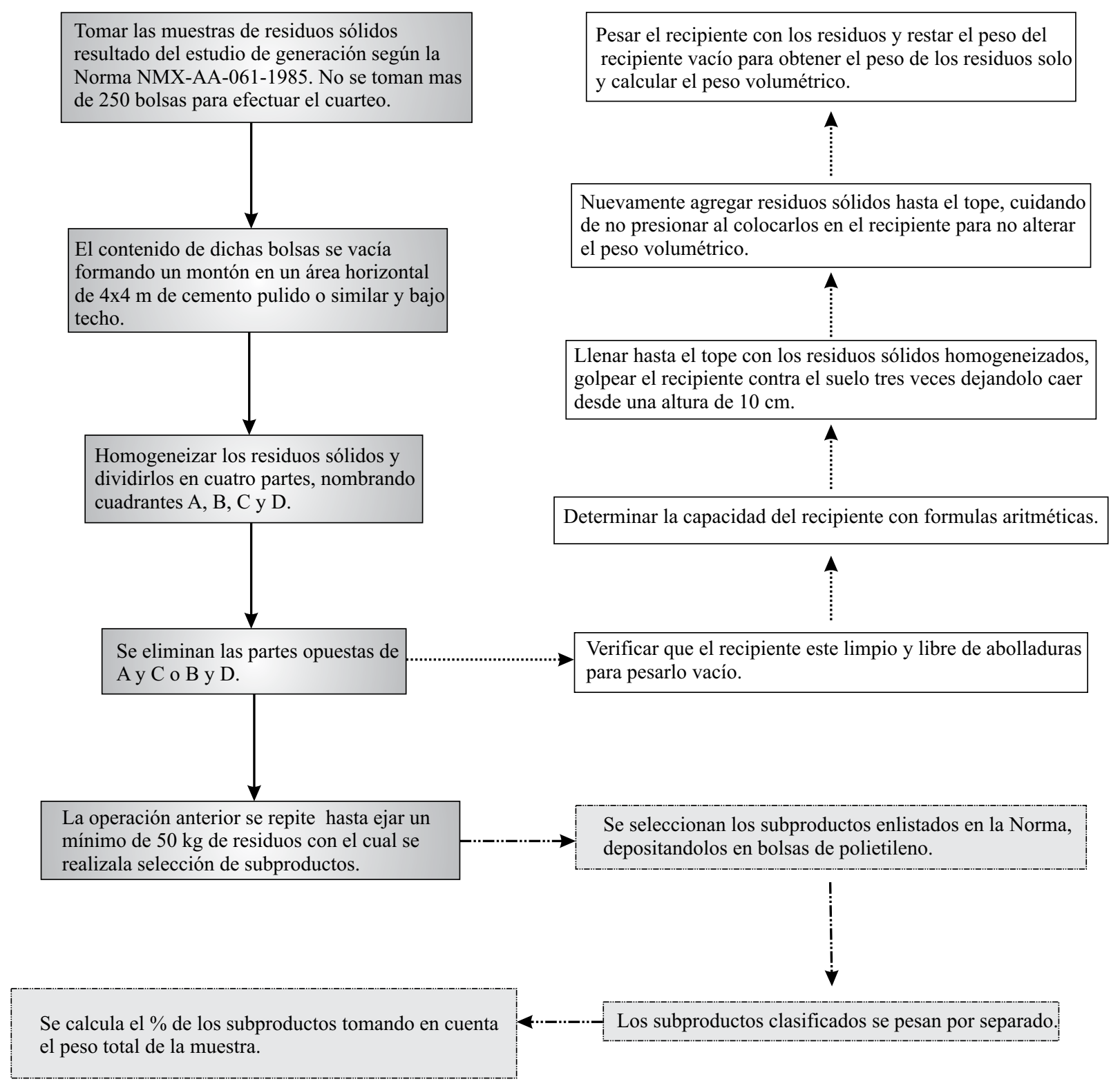

Normas técnicas aplicadas

\begin{tabular}{|l|l|l|}
\hline NMX-AA-015-1985 NMX-AA-019-1985 NMX-AA-022-1985 \\
\hline
\end{tabular}

Figura 3. Metodología para efectuar el Cuarteo, determinar el Peso Volumétrico y la Selección de Subproductos.

Trabajos más recientes que han contribuido al conocimiento geológico de la región son los realizados por IsradeAlcantara y Garduño-Monroy, 1994; Garduño-Monroy et al., 2001; Arreygue-Rocha et al., 2001; Buenrostro e Israde-Alcántara, 2002, 2003 y Pradal y Robin, 2005. Estos estudios indican que existen productos ignimbríticos, andesitas y basaltos en la secuencia volcánica del Mioceno (entre 33 y $8 \pm 0.2 \mathrm{Ma}$ ) y que en las inmediaciones del lago de Cuitzeo se presentan productos volcánicos de edad pliocuaternaria correspondientes al Arco Volcánico Transmexicano, conformados por lavas basálticas frac- turadas. Además, evidencian dos sistemas de fallas, NESW y E-W que incluso marcan la morfología del lago de Cuitzeo.

\subsection{Estratigrafía}

Desde el punto de vista estratigráfico se reconocen cuatro unidades litológicas (Figura 5) predominando, entre las rocas ígneas extrusivas, los basaltos asociados a brechas basálticas y depósitos volcanoclásticos (tobas riolíticas), 


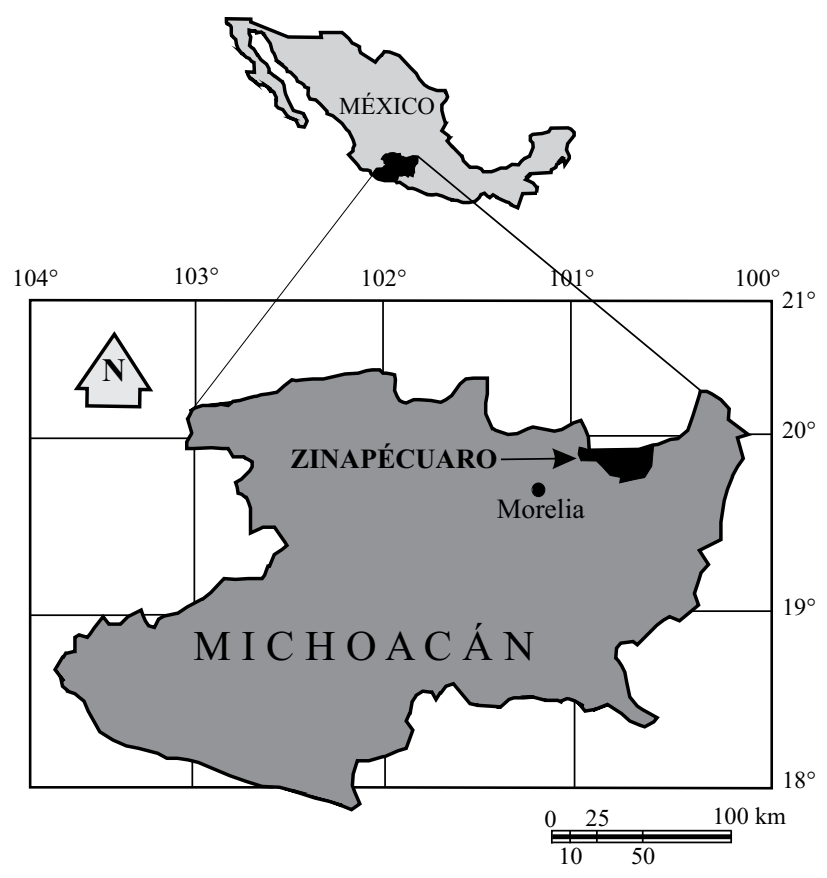

Figura 4. Localización del área de estudio.

ambos de edad Terciario Superior y Cuaternario. De manera importante se distribuye una unidad lacustre, que cubre más del 50\% de la zona estudiada; en menor cantidad, se presentan depósitos aluviales que coronan la secuencia litológica.

\subsubsection{Toba Riolítica (Tr)}

Se trata de una roca de color café claro con abundantes cristales de plagioclasa. La unidad se extiende ampliamente en la zona de estudio, formando una estructura en forma de lengüeta con orientación E-W. Así mismo, la roca se distribuye por la margen Sur del lago de Cuitzeo, el cual es un lago geotérmico limitado por fallas de dirección E-W (Santiago-Hipólito, 2005 e INEGI, 2002), la unidad es de edad Terciario Superior - Cuaternario y se caracteriza por formar lomeríos de poca elevación; superficialmente, su estructura es masiva y el intemperismo presente es somero (Figura 5).

En el afloramiento localizado en el sitio donde se pretende construir el relleno sanitario se observaron horizontes alternados de flujos piroclásticos de composición riolítica con horizontes pumicíticos, caracterizándose el primero de ellos por estar soldado; lo anterior, puede ser el reflejo de diferentes eventos deposicionales, que cuando se enfrían juntos forman una unidad de enfriamiento. Típicamente, a este tipo de depósitos se les conoce como ignimbrita, pues se trata de depósitos masivos pobremente clasificados que contiene cantidades variables de ceniza, lapilli, pómez redondeada y bloques ocasionales de más de $1 \mathrm{~mm}$ de diámetro (Cas \& Wright, 1988, Hans-Ulrich, 2004). De manera específica, se identificó una capa basal de $4.00 \mathrm{~m}$ de espesor, de grano fino con un grado signifi- cativo de soldamiento (Figura 6). Al igual que en la región de Morelia, el espesor de estos horizontes es en promedio de $4 \mathrm{~m}$ y son los que controlan la morfología de la región (Garduño-Monroy, et al., 2001). Le sobreyacen horizontes de flujo piroclástico pobremente consolidado de color claro con abundantes fragmentos de pómez, lo que le imprime una erosión diferencial en forma de hoquedades; el espesor promedio de este horizonte es de $5.00 \mathrm{~m}$. Este horizonte presenta también fragmentos de basalto; lo que permite deducir que se trata de una unidad más reciente que las rocas basálticas que afloran en la zona.

\subsubsection{Unidad Basáltica - Brecha Volcánica Basáltica $(B-B v b)$}

Esta unidad litológica está compuesta por una roca de color negro, de edad holocénica, que puede correlacionarse con la descrita por Garduño-Monroy et al., 2001, en la región de Morelia. Esta unidad litológica fue datada con el método Potasio-Argón por Pradal y Robin, 1991 en rocas muestreadas en las inmediaciones de la cabecera municipal de Zinapécuaro, obteniendo una edad de 0.8 $-0.75 \mathrm{Ma}$. La unidad de roca forma promontorios de baja altura y presenta un intenso fracturamiento que le proporciona una permeabilidad alta, su grado de intemperismo es incipiente. Se encuentra poco distribuida en el área de estudio y regularmente está asociada con brechas de la misma composición; se localiza a lo largo del borde Sur del lago de Cuitzeo, desde el poblado de San Nicolás hasta Belisario Domínguez (Figura 5), sus estructuras presentan una orientación E-W y forman escarpes que separan los depósitos lacustres de la unidad riolítica.

\subsubsection{Unidad Lacustre (la)}

Esta unidad litológica de edad cuaternaria se caracteriza por el dominio de sedimentos finos: arenas finas, limos y arcillas depositados en un ambiente lagunar somero, como lo es el Lago de Cuitzeo; la unidad se extiende muy ampliamente hacia el Sur y Este del área de estudio, abarcando cerca del cincuenta por ciento de la superficie y rodeando la estructura en forma de "lengüeta" formada por las unidades litológicas descritas anteriormente (Figura 5). Israde-Alcantara y Garduño-Monroy (1999) realizaron una descripción de una unidad localizada en la porción norte de la ciudad de Morelia que presenta las características de los afloramientos presentes en el área de estudio. Otro argumento que refuerza la correlación y edad de esta unidad se fundamenta en el hallazgo de un proboscidio que permite asignarle una edad del Pleistoceno (Israde-Alcantara et al., 1992).

\subsubsection{Unidad Aluvial (al)}

Esta unidad del Pleistoceno es la más reciente de toda la secuencia litológica. Se agrupan en esta unidad los depósitos aluviales y los de pie de monte en las laderas de las prominencias y en las estructuras volcánicas. La unidad no aparece cartografiada debido a su limitada distribución y 


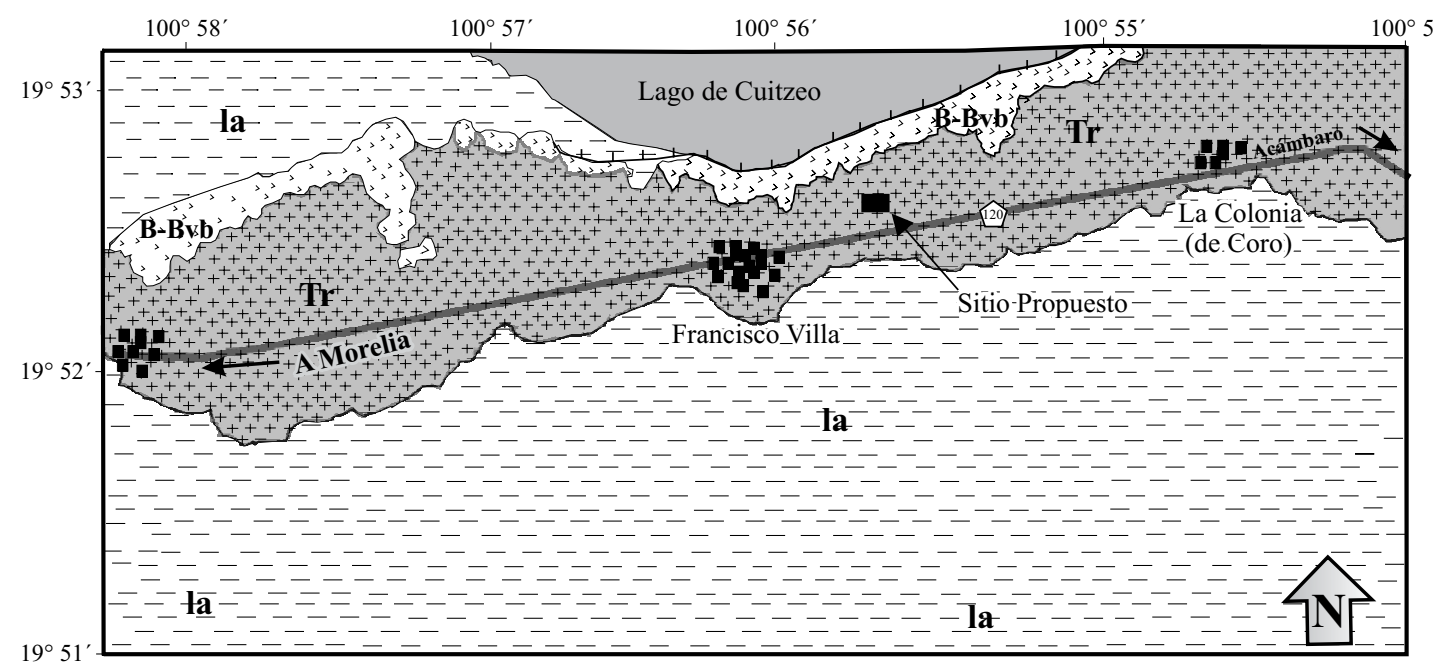

Fuente: Modificado de INEGI, 2002

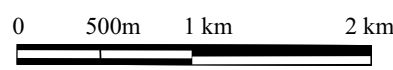

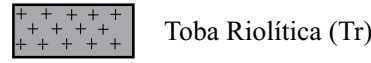

E S C A L A

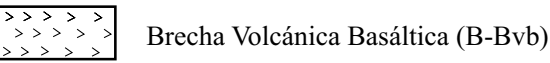

E- Depósitos Lacustres (la)

Cuerpo Hídrico

Figura 5. Mapa geológico de la zona de estudio y localización del sitio Francisco Villa.

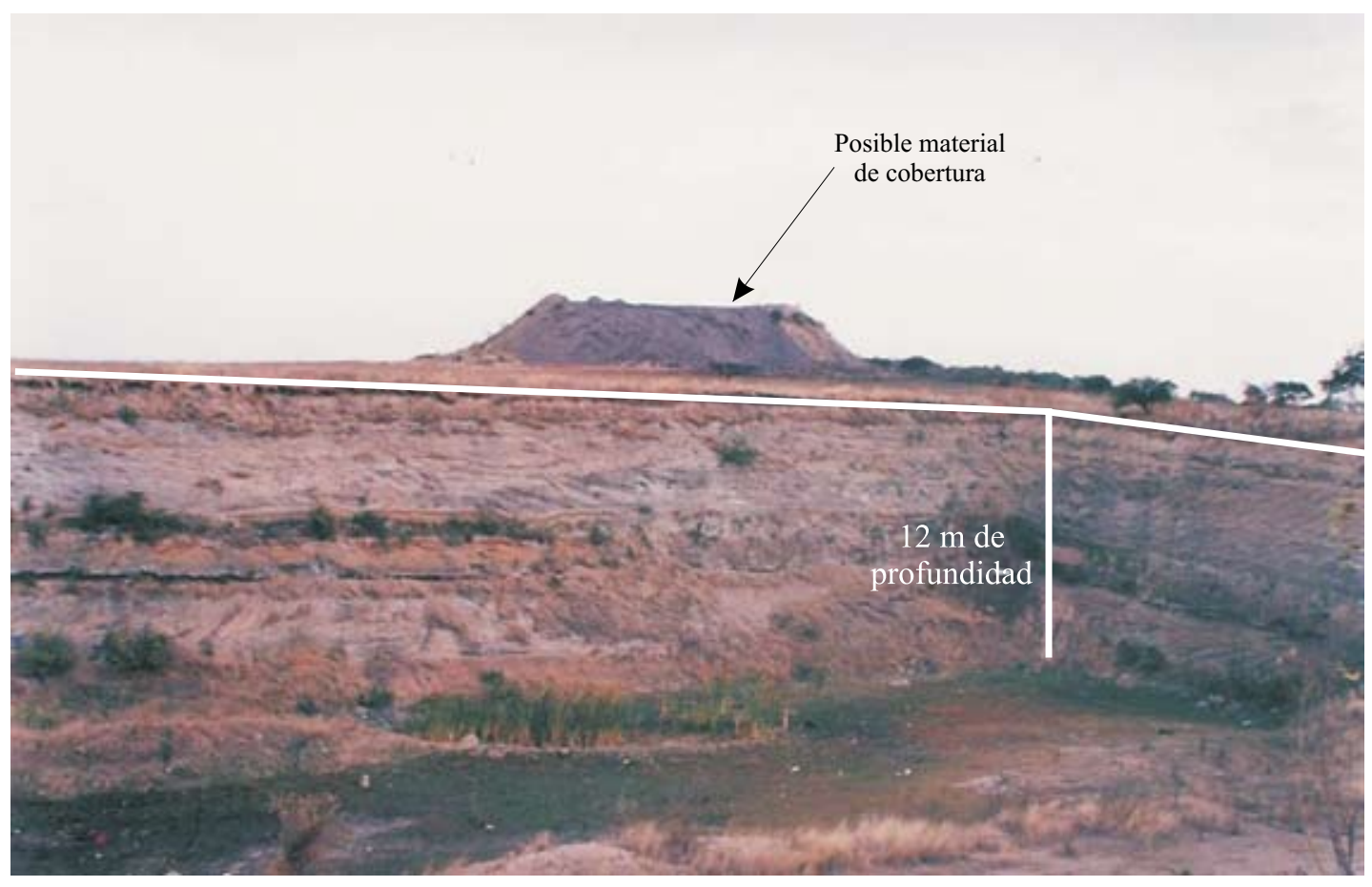

Figura 6. En primer plano, la imagen muestra el sitio propuesto (mina abandonada) para el posible confinamiento de residuos sólidos. En segundo plano se observa el material remanente de la construcción de la carretera federal y que pudiera utilizarse como material de cobertura de residuos. Fuente: Sánchez-Núñez et al., 2007. 
espesores poco significativos; sin embargo, se puede establecer que se trata de una unidad constituida por fragmentos del tamaño de las gravas y las arenas de diferente composición, su forma va de subredondeado a redondeado y no presenta cementante, motivo por el cual posee una permeabilidad alta. Su granulometría es variable puesto que está en función de la distancia de las fuentes de aporte de los detritos (CNA, 2002).

\subsection{Suelos}

Como resultado de la meteorización y erosión de las unidades litológicas antes mencionadas, en el área de estudio se presentan diferentes tipos de suelo, algunos autores como Pompa (1995) señalan que en las áreas cercanas al lago de Cuitzeo, existen suelos clasificados como verisoles y feozems. Los vertisoles son suelos que se caracterizan por su textura densa, formación de grietas profundas la mayor parte del tiempo y poseen una estructura en bloques. Son suelos jóvenes, poco profundos, algunos de ellos pedregosos y salinos, tienen alto contenido de arcilla, por lo que son poco permeables y de drenaje muy lento; el tipo de vegetación natural que crece en estos suelos es de bosque espinoso de acacia.

Los feozems se localizan intercalados con vertisoles. Son suelos en su mayoría delgados, limitados por roca o una capa de tepetate; son de permeabilidad media a baja, tienen un color negro grisáceo o gris oscuro, contienen altas cantidades de materia orgánica y son ligeramente ácidos, sin salinidad elevada. Estos suelos se desarrollan en lugares donde la evapotranspiración excede la precipitación, situación que conduce al desarrollo de una comunidad natural de gramíneas, aunque a menudo se encuentra bosque deciduo dominado por especies de encinos, como sucede en la cuenca del lago de Cuitzeo. Estos suelos tienen una fertilidad natural elevada y producen buenas cosechas.

En las zonas de mayor elevación se localizan los luvisoles, regosoles y los andosoles. Los luvisoles son sumamente arcillosos, de permeabilidad baja y drenaje lento, ricos en materia orgánica y ligeramente ácidos. Estos suelos se desarrollan principalmente sobre una gran variedad de materiales no consolidados como depósitos aluviales y coluviales. Predominan en las zonas planas o con pendientes suaves con climas templados fríos o cálidos, pero con una estación seca y otra húmeda como el que se presenta en la zona de estudio. Al igual que los luvisoles, los regosoles también se desarrollan en materiales no consolidados, pero de textura fina, por lo que se distribuyen ampliamente casi en cualquier región (Brady and Weil, 1996).

Localmente predominan los andosoles, cuyo material original, fundamentalmente son cenizas volcánicas, aunque también se desarrollan a partir de pómez, lapilli y otros productos de eyección volcánica, que son característicos del Cinturón Volcánico Mexicano. En la Tabla 1 se presentan en orden jerárquico los suelos predominantes.

Según el INEGI (2002a) los suelos de la región se clasifican como de fertilidad alta, lo que se corrobora con las extensas zonas agrícolas localizadas al sur del lago de Cuitzeo.

\subsection{Hidrología}

El Estado cuenta con tres cuencas hidrológicas principales: la Septentrional o Lerma Santiago (R-I), la Cuenca del Balsas (R-II) y la Cuenca del Sur (R-III). La zona de estudio se localiza en la cuenca del Lerma-Santiago, en la que se encuentran los lagos de Pátzcuaro, Chapala, Tuxtepec y Cuitzeo; este último, como un rasgo dominante y de influencia en la región de estudio (INEGI, 2002a; Carabias et al., 2005). Tanto el lago de Cuitzeo como los ríos de Zinapécuaro y Grande de Morelia constituyen los elementos hidrológicos más importantes que se ubican en la región administrativa No. VIII (Castelán, 2000; CNA, 2004).

La cuenca del lago de Cuitzeo, el segundo lago más grande de México, es de tipo endorreica y ocupa una superficie aproximada de $4000 \mathrm{~km}^{2}$ (Acosta, 2001). La cuenca es de edad terciaria y se caracteriza por presentar una serie de valles escalonados y estructuras en graben con topografía baja, es decir, una cuenca relativamente plana y con poca amplitud de relieve, la cual se desarrolla sobre materiales volcánicos. Localmente, el área está integrada por dos cuencas: al norte la del río Navajas y al sur la del río Zinapécuaro. La corriente principal de la primera cuenca fluye en dirección E-W y su origen es el manantial El Pozo, localizado en el poblado de Ucareo. El río las Navajas cuenta con tres afluentes (Mandujano, El Tejocote y Ojo de Agua el Sauz) que alimentan la corriente principal durante su curso en el valle de Araró. A través de dos canales, se desvía la corriente a los bordos El Rocío y Los Coyotes, mismos que vierten sus aguas al lago de Cuitzeo y zonas de cultivo. La cuenca del río Zinapécuaro se nutre de dos afluentes: el río Agrio y el río Santa Teresa que nace en el cerro El Chino; al final de su recorrido, el río Zinapécuaro desemboca en el valle de Queréndaro y sus aguas fluyen a la presa de Malpaís (Santiago-Hpólito,

Tabla 1. Distribución porcentual de los suelos en Michoacán.

\begin{tabular}{|c|c|c|}
\hline Tipo de Suelo & Superficie $\left(\mathbf{k m}^{2}\right)$ & $\%$ Estatal \\
\hline Vertisoles & 18853 & 32.18 \\
\hline Regosoles & 18056 & 30.82 \\
\hline Andosoles & 7013 & 11.97 \\
\hline Luvisoles & 6280 & 10.72 \\
\hline Cambisoles & 5038 & 8.6 \\
\hline Feozems & 3345 & 5.71 \\
\hline Total & 58585 & 100 \\
\hline
\end{tabular}

Fuente: Sánchez-Núñez et al., 2007 con datos del INEGI, 2002. 
2005). Hacia la margen occidental del lago, las corrientes fluviales presentan una red de tipo arborescente y, al E-NE se desarrolla un drenaje de tipo radial, debido a las estructuras dómicas y a los aparatos volcánicos. Localmente, las corrientes más importantes son: El Tejocote, El Perro, El arenal, Vuelta del Cerro y los Duranes.

\subsection{Estructura Socio - Económica}

Para realizar cualquier propuesta para un sitio de disposición final de residuos sólidos urbanos, es indispensable la información relativa a la población; a continuación se presentan datos que, inicialmente, son de carácter descriptivo pero que, más adelante se amalgaman con los elementos geológicos para dar cimiento a la propuesta final del estudio.

Los datos históricos sobre la evolución de la población de Zinapécuaro muestran que, hasta el año de 1950 se registraron 20 mil 208, para el año de 1995 se tenían 48 mil 902 y para el año 2000 fue de 48 mil 819 habitantes. Como puede observarse, en la década de los cincuenta la población del municipio representaba el $1.42 \%$ de la población total de Michoacán, descendiendo al $1.26 \%$ en 1995 y descendiendo aún más para el año 2000 con el 1.23\%. Es decir, la población del municipio ha tendido a perder importancia relativa a pesar de que no ha dejado de crecer en términos absolutos. La densidad de población del municipio para el año 2000 fue de $94 \mathrm{hab} / \mathrm{km}^{2}$ y su tasa de crecimiento fue del 2\% (COPLADE, 2002; INEGI, 2000). La marginación y la tenencia de la tierra son variables ambientales importantes para el cálculo de la generación de residuos sólidos, así como para la gestión ante los propietarios del terreno donde se pretende construir dicho relleno. En cuanto a la marginación, el COPLADE en 2002 (Tabla 2) indica para 1980 un índice de -4.9 y para 1990 de -0.5 ; concluyendo con lo anterior que el municipio de Zinapécuaro se ubica en un grado alto. Respecto a la tenencia de la tierra, el Municipio se caracteriza por ser de carácter ejidal, con 13,372 has, con 4369 has comunales y de propiedad privada con 19764 has.

\section{Resultados y discusión}

\subsection{Generación de residuos sólidos urbanos}

Para contar con información confiable y actual sobre los parámetros de generación per-cápita diaria, peso volumétrico in situ y la composición de los residuos sólidos domiciliarios en Zinapécuaro, se llevó a cabo el estudio de generación durante ocho días, tomando como base las Normas Mexicanas NMX-AA-061-1985, NMX-AA-0151985, NMX-AA-022-1985 y NMX-AA-019-1985.

El estudio de generación de residuos sólidos en una comunidad debe contemplar un muestreo de tres estratos
Tabla 2. Indicadores de Marginación en Zinapécuaro, Michoacán. (\%).

\begin{tabular}{lc}
\hline Mayores de 15 años analfabetos & 18.0 \\
Mayores de 15 años sin primaria completa & 54.9 \\
Ocupantes de viviendas particulares: & \\
Sin drenaje ni excusado & 30.4 \\
Sin energía eléctrica & 8.6 \\
Sin agua entubada & 21.1 \\
Con hacinamiento & 61.3 \\
Con piso de tierra & 26.7 \\
Habitantes en localidades menores a 5 mil habitantes & 72.6 \\
Población ocupada con ingresos menores a 2 salarios mínimos & 70.9
\end{tabular}

Fuente: Sánchez-Núñez et al., 2007 con datos del COPLADE, 2002.

socioeconómicos (alto, medio y bajo), sin embargo, para realizar este estudio se muestreó únicamente el estrato medio, debido a que el COPLADE (2002) ubica al municipio de Zinapécuaro con un grado de marginación alto; además, el criterio se reforzó con visitas a la cabecera municipal donde se pudo observar que la población es homogénea.

Para tomar una muestra confiable de los residuos sólidos generados que fuese representativa, se seleccionó un riesgo del $10 \% \mathrm{y}$, con base en lo establecido en la Norma, se adopta un tamaño de premuestra de ochenta casas habitación que fueron muestreadas durante un periodo de siete días. El universo de trabajo se determinó para trescientas casas, que es un valor comprendido en el intervalo que la Norma determina para realizar el estudio de generación.

\subsection{Análisis estadístico}

Se realizó con base en la metodología señalada en la Norma NMX-AA- 061-1985. De los siete datos obtenidos de cada casa habitación durante los siete días de muestreo, se calculó el promedio de la generación per cápita, con lo que se obtienen ochenta valores promedio; para poder realizar una prueba de rechazo, tal y como lo establece la Norma, estos valores promedio se ordenaron en forma ascendente (Tabla 3 ).

\subsubsection{Prueba de rechazo de observaciones}

Se realizó un análisis de rechazo de observaciones sospechosas, aplicando el criterio de Dixon; este método considera que las observaciones sospechosas, pueden ser muy pequeñas o muy grandes, de manera tal que se sospeche que en ambos casos deban rechazarse. Con base en los datos de muestreo, se sospecha de las primeras cuatro y las últimas cuatro observaciones por lo que se calculó el valor del estadístico " $r$ " como se indica en la Norma NMX-AA-061-1985.

Con un arreglo de menor a mayor valor de la generación per-cápita, se pudo observar que los valores oscilan entre 0.09 y $1.23 \mathrm{~kg} / \mathrm{hab} /$ día como límite inferior y superior, respectivamente. 
Tabla 3. Promedio de la generación per cápita (datos ordenados)

\begin{tabular}{|c|c|c|c|c|c|c|c|}
\hline $\begin{array}{l}\text { Número } \\
\text { ascendente }\end{array}$ & $\begin{array}{l}\text { Promedio } \\
\mathrm{Kg} / \text { hab•día }\end{array}$ & $\begin{array}{l}\text { Número } \\
\text { ascendente }\end{array}$ & $\begin{array}{l}\text { Promedio } \\
\mathrm{Kg} / \text { hab•día }\end{array}$ & $\begin{array}{c}\text { Número } \\
\text { ascendente }\end{array}$ & $\begin{array}{l}\text { Promedio } \\
\mathrm{Kg} / \text { hab•día }\end{array}$ & $\begin{array}{l}\text { Número } \\
\text { ascendente }\end{array}$ & $\begin{array}{l}\text { Promedio } \\
\mathrm{Kg} / \text { hab•día }\end{array}$ \\
\hline 1 & 0.09 & 21 & 0.48 & 41 & 0.61 & 61 & 0.76 \\
\hline 2 & 0.16 & 22 & 0.48 & 42 & 0.61 & 62 & 0.78 \\
\hline 3 & 0.17 & 23 & 0.49 & 43 & 0.62 & 63 & 0.79 \\
\hline 4 & 0.31 & 24 & 0.49 & 44 & 0.62 & 64 & 0.81 \\
\hline 5 & 0.31 & 25 & 0.51 & 45 & 0.62 & 65 & 0.81 \\
\hline 6 & 0.31 & 26 & 0.51 & 46 & 0.63 & 66 & 0.81 \\
\hline 7 & 0.32 & 27 & 0.53 & 47 & 0.63 & 67 & 0.81 \\
\hline 8 & 0.35 & 28 & 0.54 & 48 & 0.65 & 68 & 0.83 \\
\hline 9 & 0.36 & 29 & 0.54 & 49 & 0.65 & 69 & 0.83 \\
\hline 10 & 0.39 & 30 & 0.54 & 50 & 0.65 & 70 & 0.86 \\
\hline 11 & 0.39 & 31 & 0.55 & 51 & 0.67 & 71 & 0.88 \\
\hline 12 & 0.42 & 32 & 0.56 & 52 & 0.67 & 72 & 0.91 \\
\hline 13 & 0.42 & 33 & 0.58 & 53 & 0.68 & 73 & 0.93 \\
\hline 14 & 0.44 & 34 & 0.58 & 54 & 0.69 & 74 & 0.94 \\
\hline 15 & 0.45 & 35 & 0.59 & 55 & 0.70 & 75 & 0.95 \\
\hline 16 & 0.45 & 36 & 0.59 & 56 & 0.74 & 76 & 0.96 \\
\hline 17 & 0.45 & 37 & 0.60 & 57 & 0.74 & 77 & 0.97 \\
\hline 18 & 0.45 & 38 & 0.60 & 58 & 0.74 & 78 & 1.12 \\
\hline 19 & 0.47 & 39 & 0.61 & 59 & 0.74 & 79 & 1.14 \\
\hline 20 & 0.48 & 40 & 0.61 & 60 & 0.76 & 80 & 1.23 \\
\hline
\end{tabular}

Fuente: Sánchez-Núñez et al., 2007.

\section{Dudando de los elementos máximos:}

Por medio de la expresión matemática (1) se determina la "r" calculada para compararla con la " $\mathrm{r}_{1-\sigma / 2}$ " de la tabla No. 2 del Apéndice de la Norma²

$$
x_{n}=\frac{x_{n}-x_{i}}{x_{j}}
$$

Los valores considerados fueron los siguientes:

$n=80 \quad$ Número de observaciones o elemento mayor

$l=1 \quad$ El elemento menor

$i=75 \quad \mathrm{n}-(\mathrm{j}-l)$

$j=4 \quad$ Elemento del muestreo que define el límite inferior del intervalo de sospecha en la cola superior de los datos ya ordenados

Sustituyendo valores en (1)

$$
r=\frac{1.23-0.95}{1.23-0.31}=0.304
$$

Con: $\alpha=0.10$ de riesgo se tiene que el valor del percentil es de 0.95 , el cual se comparó con la tabla de rechazo de observaciones distintas de la Norma Técnica.

Las observaciones sospechosas se rechazan o aceptan, de acuerdo con los siguientes criterios:

$r>r(1-\alpha / 2)$ Se rechaza la observación sospechosa $\mathrm{r}<\mathrm{r}(1-\alpha / 2)$ Se acepta la observación sospechosa Para $90 \%$ de confiabilidad $\mathrm{r}_{1-\sigma / 2}=0.406$

$$
r=0.304<0.406=r_{1-\sigma / 2}
$$

${ }_{2}^{2}$ Para mayor detalle sobre la expresión No. 1, consultar el apéndice de la Norma NMX-AA-061-1985.
Por lo tanto, para Zinapécuaro se aceptó el elemento 80 de la premuestra.

De igual modo, dudando de los elementos mínimos, se aplicó la expresión No. 2:

$$
r=\frac{x_{j}-x_{l}}{x_{i}-x_{l}}
$$

Los valores considerados fueron los siguientes:

$$
\begin{aligned}
& n=80 \\
& l=1 \\
& i=75 \\
& j=4
\end{aligned}
$$

Sustituyendo valores en (2):

$$
r=\frac{0.31-0.09}{0.95-0.09}=0.2558
$$

Con: $1-\sigma / 2$ se consultó la tabla de rechazo de observaciones distintas de la Norma Técnica.

Para $\alpha=0.10$ de riesgo

Para $90 \%$ de confiabilidad $r_{1-\sigma / 2}=0.406$
$r=0.1774<0.406=r_{1-\sigma / 2}$

Con el valor obtenido se aceptó el elemento número 1 de la premuestra. Por lo tanto, los dos valores encontrados se consideran como verdaderos.

Una vez aceptados todos los elementos de la premuestra se calcularon los siguientes estadísticos: Promedio $=$ 0.62 , Mediana $=0.219$ y Desviación Estándar $=0.61$. Con los valores calculados se procedió a obtener el tamaño real de la muestra empleando la distribución de la " $\mathrm{t}$ " de 
Student mediante la expresión (3).

$$
n_{1}=\left(\frac{t^{*} s}{E}\right)^{2}
$$

Donde:

$$
\begin{aligned}
n_{1}= & \text { Tamaño real de la muestra } \\
s= & \text { Desviación estándar de la premuestra. } \\
E= & \text { Error muestral (la Norma recomienda un valor en- } \\
& \text { tre } 0.04 \text { y } 0.07 \text { ) } \\
t= & \text { Percentil de la distribución " } \mathrm{t} \text { " de Student corres- } \\
& \text { pondiente al nivel de confianza definido por el } \\
& \text { riesgo empleado. }
\end{aligned}
$$

De la Tabla 3 del apéndice de la Norma obtenemos para 80 grados de libertad y un valor para " $t$ " de 1.294

Sustituyendo valores en la ecuación (3):

$$
n_{1}=50.19
$$

$$
n_{1}=\left(\frac{1.294^{*} 0.219}{0.04}\right)^{2}
$$

entonces el tamaño real de la muestra es de 50 elementos.

$$
n_{1}=50<n=80
$$

La muestra requerida es menor al número de muestras que se tomaron, por lo tanto, ésta última se considera como la muestra real. La premuestra se consideró como la muestra real, por lo tanto, $\boldsymbol{n}=\boldsymbol{8 0}$ por lo que no hubo necesidad de realizar un nuevo muestreo.

\subsubsection{Análisis de confiabilidad}

Una vez determinado el tamaño de la muestra, fue necesario saber si se aceptan o rechazan los parámetros estadísticos de la muestra como los elementos del universo de trabajo, por lo que se realizó una prueba de hipótesis de dos colas, con la finalidad de definir si la media muestral difería de la media poblacional.

Para realizar este análisis fue necesario establecer las siguientes hipótesis:

$$
\begin{aligned}
& H_{0}: \bar{x}=\mu \\
& H_{a}: \bar{x} \neq \mu
\end{aligned}
$$

Donde $H_{0}$ es la hipótesis nula que establece que la media obtenida de la premuestra no difiere significativamente de la media poblacional, mientras que la hipótesis alternativa $\left(H_{\alpha}\right)$ proponía una diferencia significativa entre la media obtenida de la muestra y la media poblacional. Si se aceptaba la hipótesis nula podemos decir que los estadísticos de la muestra podían ser tomados como los parámetros del universo de trabajo; por el contrario, si se aceptaba la hipótesis alternativa sería necesario realizar un nuevo muestreo y desechar el analizado. Analizando los percentiles de la distribución " $t$ ", se obtuvo lo siguiente:

$$
t_{c a l}=\frac{E}{s} \sqrt{n}
$$

sustituyendo los valores en (4), se tiene:

$$
\begin{gathered}
t_{c a l}=\frac{0.04}{0.219} \sqrt{80} \\
t_{c a l}=1.633
\end{gathered}
$$

\section{Criterio de decisión}

$t_{c a l}<t(1-\alpha / 2)$ se acepta la hipótesis nula y se rechaza la hipótesis alternativa.

$\mathrm{t}_{\text {cal }}>\mathrm{t}(1-\alpha / 2)$ Se rechaza la hipótesis nula y se acepta la hipótesis alternativa

Teniendo como referencia la tabla de distribución " $\mathrm{t}$ " de Student (tabla 3 del anexo de la Norma) y asumiendo un riesgo $\sigma=0.10$ y un nivel de significancia de $(1-\sigma / 2)=0.95$ se tiene que: $t_{0.95}=1.667$

Comparando el valor calculado con el de la tabla $\mathrm{t}_{0.95}$, se establece lo siguiente:

$$
1.633=t_{\text {cal }}<t_{0.95}=1.667
$$

Este valor se puede interpretar de las formas siguientes:

1. Se acepta la hipótesis: $H_{0}: \bar{x}=\mu$

2. La media muestral posee un $95 \%$ de confiabilidad al igual que la media poblacional, por lo tanto se concluyó que la media muestral se podía utilizar como media poblacional.

Con base en el análisis estadístico realizado al muestreo de los residuos sólidos en la cabecera municipal de Zinapécuaro, se estableció que la generación promedio de residuos sólidos urbanos es de $\mathbf{0 . 6 2} \mathbf{~} \mathbf{k g} / \mathbf{h a b} /$ día

\subsubsection{Determinación del Peso Volumétrico}

Una vez concluido el pesaje de las muestras, se procedió al cuarteo para conocer el peso volumétrico de acuerdo a lo indicado en las Normas NMX-AA-015-1985 y NMXAA-019-1985 respectivamente, dicho peso se calculó con la siguiente expresión:

Donde:

$$
P v=P / V
$$

$P v=$ Peso volumétrico de los residuos sólidos de la muestra en $\mathrm{kg} / \mathrm{m}^{3}$

$P=$ Peso de los residuos de la muestra en $\mathrm{kg}$ (valor promedio de las 7 muestras)

$V=$ Volumen del recipiente empleado para la determi nación en $\mathrm{m}^{3}$

Sustituyendo valores en (5).

$$
\begin{aligned}
& P v=52.52 / 208 \\
& P v=252.54 \mathrm{~kg} / \mathrm{m}^{3}
\end{aligned}
$$

Los análisis estadísticos aplicados para obtener el peso volumétrico y la desviación estándar, indicaron que el peso de los residuos sólidos que se generan en Zinapécuaro es de $252.54 \mathbf{k g} / \mathbf{m}^{3}$ (Tabla 4). 


\subsubsection{Selección y Cuantificación de los Subproductos}

Con los residuos sólidos utilizados en la determinación del peso volumétrico, se llevó a cabo diariamente, la selección y cuantificación de subproductos con base en la Norma NMX-AA-022-1985. Los subproductos seleccionados se pesaron, anotando el resultado en la cédula correspondiente, en forma de porcentajes en peso de cada uno de los subproductos; lo anterior se calculó con la expresión 6:

Donde:

$$
P S=P_{l} / P^{*} 100(6)
$$

$P S=$ Porcentaje en peso del subproducto considerado.

$P_{I}=$ Peso del subproducto considerando, descontando el peso de la bolsa empleada para almacenarlos temporalmente $(\mathrm{kg})$.

$P=$ Peso total de la muestra empleada para la selección y cuantificación de los subproductos.

Es importante mencionar que en ningún caso, se presentaron pérdidas mayores al $5 \%$, valor aceptable por la norma Técnica.

Finalmente, se realizó un análisis estadístico de cada uno de los subproductos antes listados, con los siete valores diarios determinados durante el período de muestreo y se obtuvo la media aritmética por subproductos (Tabla 5).

Es importante resaltar (Figura 8) que el pañal desechable fue uno de los residuos que sobresalió en el proceso de separación de subproductos.

\subsection{Criterios para la selección del sitio de disposición final}

Para realizar el presente análisis se tomó como base la Norma Oficial Mexicana NOM-083-SEMARNAT-2003 en la cual se exponen las especificaciones de protección ambiental para la selección del sitio, diseño, construcción, operación, monitoreo, clausura y obras complementarias de un sitio de disposición final de residuos sólidos urbanos y bajo el argumento de que dicha obra de infraestructura posee una vocación social, que beneficiará a la propia co-

Tabla 4. Determinación del peso volumétrico in situ de los residuos sólidos generados en el Municipio de Zinapécuaro, Michoacán.

\begin{tabular}{llcccc}
\hline Día & $\begin{array}{c}\text { Peso } \\
\text { tambo } \\
\mathbf{( k g )}\end{array}$ & $\begin{array}{c}\text { Peso tambo }+ \\
\text { residuos } \\
\mathbf{( k g )}\end{array}$ & $\begin{array}{c}\text { Peso } \\
\text { Residuos } \\
\mathbf{( k g )}\end{array}$ & $\begin{array}{c}\text { Volumen } \\
\left(\mathbf{m}^{\mathbf{3}}\right)\end{array}$ & $\begin{array}{c}\text { Peso } \\
\text { volumétrico } \\
\left(\mathbf{k g} / \mathbf{m}^{\mathbf{3}}\right)\end{array}$ \\
\hline 1 & 15 & 66 & 51 & 0.208 & 245.19 \\
2 & 15.4 & 67 & 51.6 & 0.208 & 248.08 \\
3 & 15 & 68 & 53 & 0.208 & 254.81 \\
4 & 15.6 & 68 & 52.4 & 0.208 & 251.92 \\
5 & 15.8 & 69 & 53.2 & 0.208 & 255.77 \\
6 & 15.5 & 70 & 54.5 & 0.208 & 262.02 \\
7 & 15 & 67 & 52 & 0.208 & 250.00 \\
& & & & Promedio & $\mathbf{2 5 2 . 5 4}$ \\
\hline
\end{tabular}

Fuente: Sánchez-Núñez et al., 2007. munidad y al medio donde ésta se desarrolla.

La Tabla 6 muestra los requerimientos previos que deben cumplir las áreas que serán destinadas para la construcción de sitios de disposición final, en ésta se muestran los requisitos para las tres categorías que marca la Norma Oficial de referencia; es importante señalar que, con base en los análisis estadísticos aplicados a los RSU, el sitio de disposición para Zinapécuaro está clasificado como Tipo "C"; lo anterior debido a que el tonelaje de residuos que se generan en la comunidad y que son recibidos en el actual tiradero es mayor a 10 y menor a 50 Ton/día.

Atendiendo las especificaciones que marca la normatividad, el sitio de disposición final de RSU para Zinapécuaro debe comprender: un levantamiento topográfico, un estudio geotécnico y el estudio de generación de residuos. En el caso del estudio topográfico, debido a que se trata de una zona donde se extraían materiales para la construcción, la cavidad ya fue construida y solo restaría dar una inclinación al fondo de dicha cavidad; en lo referente al estudio geotécnico, éste se enfocó al estrato que soportaría las celdas de residuos y finalmente, se desarrolló el estudio de generación de RSU y constituye uno de los pilares de esta investigación (Tabla 6).

Con el fin de atender la situación del tiradero a cielo abierto que opera hace más de 20 años en la comunidad y que genera un total de 19.8 toneladas de RSU por día (Santiago-Hipólito, 2005 y Flores-Flores, 2005), las autoridades municipales mostraron interés en aprovechar las cavidades de minas abandonadas (Figura 5), por lo que los esfuerzos se enfocaron en la prospección en éstos bancos de materiales pétreos.

\subsubsection{Valoración de los sitos propuestos.}

Después de realizar un amplio reconocimiento de campo, se seleccionaron dos sitios, cuyas características se muestran en la Tabla 7. La tabla muestra que ambos sitios presentaron condiciones muy similares, sin embargo, la caracterización detallada proporcionó elementos que reforzaron la decisión final.

\subsubsection{Sitio Los Duranes}

Es una estructura de $157500 \mathrm{~m}^{3}$ de capacidad que se ubica al pie de la carretera No. 120 con dirección Zinapécuaro-Morelia, a una distancia aproximada de 5.8 $\mathrm{km}$ de la cabecera municipal. En el sitio se localizan líneas de transmisión de energía eléctrica (entre la carretera y el cuerpo de la estructura), por lo que si se toman en consideración los criterios de derecho de vía, tanto de la carretera como de las líneas de energía, correspondientes a la Secretaría de Comunicaciones y Transportes (SCT) y a la Comisión Federal de Electricidad (CFE) respectivamente, el sitio violenta lo establecido legalmente; aunque dichos criterios no aparecen en la NOM de referencia.

Otros criterios que descalifican este sitio son los siguientes:

- Su cercanía a la población, la estructura prácticamen- 
Tabla 5. Composición de los residuos sólidos generados en Zinapécuaro, Michoacán

\begin{tabular}{lclclc}
\hline \multicolumn{1}{c}{ Residuo } & $\%$ & \multicolumn{1}{c}{ Residuo } & $\%$ & \multicolumn{1}{c}{ Residuo } & $\%$ \\
\hline Cuero & 0.3 & Otros & 0.5 & PET & 2 \\
Fibra Sintética & 0.3 & Loza y cerámica & 0.6 & Papel & 2.7 \\
Lata & 0.3 & Cartón & 1 & Residuo fino & 3 \\
Madera & 0.4 & Material de construcción & 1.2 & Residuos de jardín & 4 \\
Fibra dura vegetal & 0.4 & Cartón encerado & 1.2 & Vidrio de color & 4.9 \\
Hueso & 0.5 & Material Ferroso & 1.5 & Plástico de película & 5 \\
Algodón & 0.5 & Trapo & 1.6 & Vidrio transparente & 6.4 \\
Material no ferroso & 0.5 & Plástico rígido & 1.8 & Pañal desechable & 13.1 \\
& & & & Residuos alimenticios & 46.1 \\
\hline
\end{tabular}

te se localiza dentro de una comunidad (José María Morelos) e incluso forma una barrera natural que evita el crecimiento de la mancha urbana.

- Topográficamente se localiza entre la Mesa El Palillo y el Cerro San Martín; lo que se manifiesta en una pendiente pronunciada, formando la desembocadura del arroyo entre las dos prominencias.

- Estructuralmente se localiza cerca de una fractura geológica, lo que puede conjugarse con la topografía y generar inestabilidad en el terreno.

- Finalmente, a $150 \mathrm{~m}$ al Norte de la estructura se localiza un afloramiento de rocas basálticas intensamente fracturadas, que imprimen una porosidad secundaria alta, que a futuro pudiera influir en la contaminación de los mantos acuíferos debido a la generación de lixiviados.

Por lo anterior, el sitio Los Duranes no se recomienda para la construcción del relleno sanitario, a pesar de que cumple con varios de los lineamientos marcados en la normatividad ambiental vigente.

\subsubsection{Sitio Francisco Villa}

Es una estructura de $137149 \mathrm{~m}^{3}$ de capacidad, que se ubica a $200 \mathrm{~m}$ al Norte de la carretera No. 120 con direc- ción Zinapécuaro-Morelia, a una distancia aproximada de $11.5 \mathrm{~km}$ de la cabecera municipal. La población más cercana se localiza a $1000 \mathrm{~m}$ (Colonia el Coro) y a $1800 \mathrm{~m}$ de la población de Francisco Villa. Aproximadamente a 850 $\mathrm{m}$ al Norte se localiza el cuerpo de agua más cercano (lago de Cuitzeo), las líneas de transmisión eléctrica mencionadas en el sitio anterior se localizan a $200 \mathrm{~m}$. Estos criterios que aparecen en la Norma Oficial Mexicana de referencia, permiten considerar este sitio con buena posibilidad para la construcción del sitio de disposición final.

Otros criterios que consolidan el sitio Francisco Villa son los siguientes:

- Topográficamente se localiza en un terreno con una pendiente suave (aproximadamente del $2 \%$ ), lo que favorecería de forma natural los escurrimientos superficiales hacia el lado opuesto del lago de Cuitzeo. La configuración topográfica en este lugar adquiere la función de un "parteaguas", donde una porción de la precipitación escurre hacia el lago y otra porción escurre hacia la planicie situada al sur de dicho lago; este mismo efecto tendrían los lixiviados que se generarán al interior de las celdas de confinamiento.

- Estructuralmente, el sitio se localiza a $850 \mathrm{~m}$ al sur de

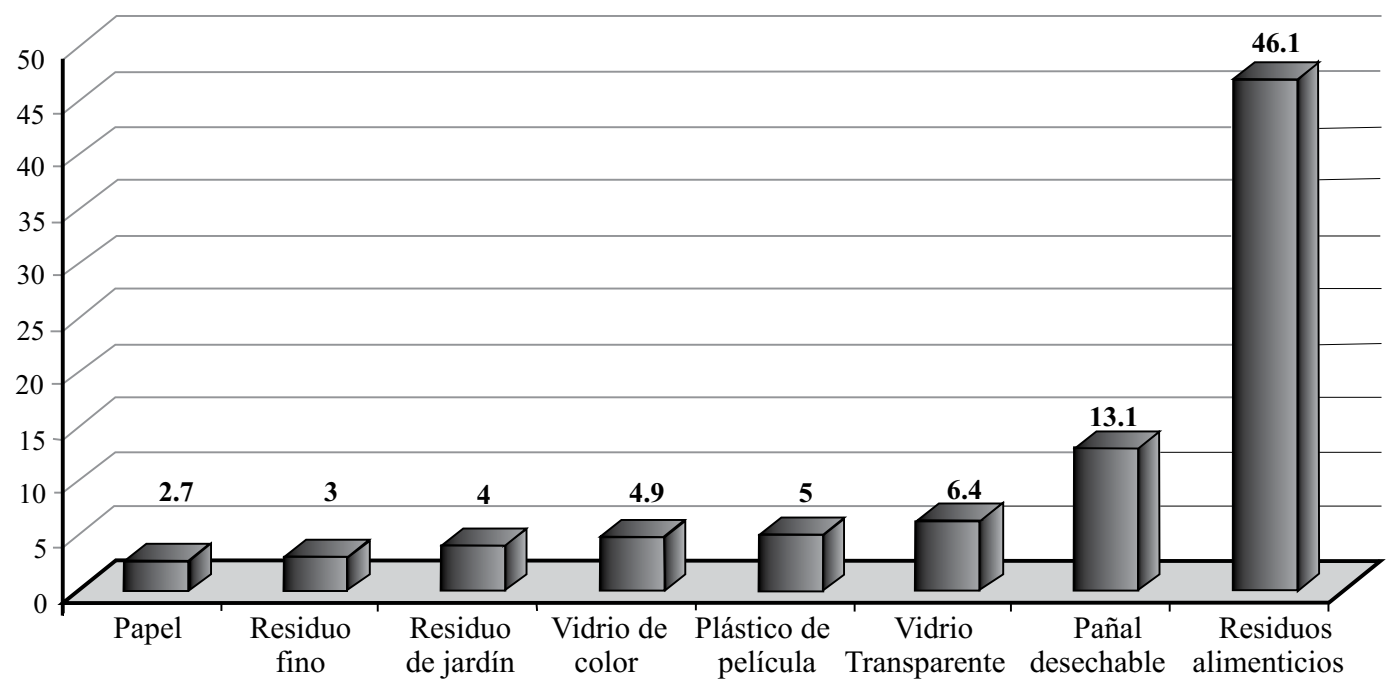

Figura 8. Principales subproductos generados en la Cabecera Municipal de Zinapécuaro, Michoacán. Fuente: Sánchez-Núñez et al., 2007. 
Tabla 6. Estudios y análisis previos requeridos para la construcción de sitios de disposición final de acuerdo a la Norma Oficial Mexicana NOM-083SEMARNAT-2003.

\begin{tabular}{|c|c|c|c|c|c|}
\hline \multicolumn{3}{|c|}{ Estudios y análisis } & \multicolumn{3}{|c|}{ Tipo } \\
\hline $\begin{array}{l}\text { Geológico y } \\
\text { Geohidrológico* }\end{array}$ & Marco regional & $\begin{array}{l}\text { Definir unidades estratigráficas } \\
\text { Reconocimiento de estructuras, fracturas, fallas, } \\
\text { pliegues } \\
\text { Identificación de cuencas y subcuencas }\end{array}$ & $\mathrm{X}$ & & \\
\hline $\begin{array}{l}\text { Evaluación Geológica y } \\
\text { Geohidrológica** }\end{array}$ & Marco local & $\begin{array}{l}\text { Identificar unidades hidrogeológicas } \\
\text { Determinar parámetros hidráulicos } \\
\text { Definir dirección de flujo subterráneo } \\
\text { Medir propiedades físicas y químicas del agua. }\end{array}$ & $X$ & $\mathrm{X}$ & \\
\hline Hidrológico* & $\begin{array}{l}\text { Marco regional y } \\
\text { local }\end{array}$ & $\begin{array}{l}\text { Ubicación de cuerpos de agua: ríos, lagos, lagunas, } \\
\text { presas } \\
\text { Definición de tipos de drenaje } \\
\text { Definir direcciones de escurrimiento }\end{array}$ & $\mathrm{X}$ & $\mathrm{X}$ & \\
\hline Topográfico & Marco local & Levantamiento planimétrico y altimétrico & $\mathrm{X}$ & $\mathrm{X}$ & $\mathbf{X}$ \\
\hline Geotécnico* & Marco local & $\begin{array}{l}\text { Estudios de campo: } \\
\text { Exploración para ubicar el muestreo } \\
\text { Identificación de muestras } \\
\text { Determinación de la permeabilidad } \\
\text { Estudios de laboratorio: } \\
\text { Análisis granulométrico } \\
\text { Determinar la permeabilidad } \\
\text { Determinar límites de Atterberg } \\
\text { Prueba de consolidación unidimensional } \\
\text { Prueba de resistencia al esfuerzo cortante }\end{array}$ & $X$ & $\mathrm{X}$ & $\mathbf{X}$ \\
\hline \multicolumn{2}{|c|}{$\begin{array}{l}\text { Generación y Composición Marco local } \\
\text { de los RSU* }\end{array}$} & $\begin{array}{l}\text { Estudios de Generación en campo: } \\
\text { Determinar la generación per cápita } \\
\text { Aplicar el método de cuarteo } \\
\text { Determinar el Peso Volumétrico } \\
\text { Determinar los Subproductos }\end{array}$ & $\mathrm{X}$ & $\mathrm{X}$ & $\mathbf{X}$ \\
\hline Generación de Biogás** & & & $X$ & $\mathrm{X}$ & \\
\hline Generación de Lixiviado & & & $\mathrm{X}$ & $\mathrm{X}$ & \\
\hline
\end{tabular}

Elaborada a partir de los criterios marcados en la NOM-083-SEMARNAT-2003. *Estudios realizados en esta investigación. **Estudios altamente recomendados para realizarse.

una falla, pero que por sus características y localización no tendría influencia en la estabilidad del talud donde se ubicaría el sitio de disposición de residuos.

- Un elemento fundamental para la posible aceptación del sitio Francisco Villa es la condición que guardan los diferentes estratos de roca que fueron cortados durante la explotación de los materiales pétreos, ya que dejaron expuestas capas de roca con baja permeabilidad (Figura 7), hecho que se corrobora por la acumulación de agua pluvial en la parte profunda de la ex-mina; lo anterior se puede atribuir a que se trata de un flujo de pómez con soldamiento y espesor suficiente $(3.65 \mathrm{~m})$ para tener baja porosidad y permeabilidad; aunque debe aclararse que no se presenta ninguna capa arcillosa como lo indica la Norma Oficial Mexicana.

- Otro elemento importante es el material de cobertura que se utilizaría en el relleno sanitario, en este caso, existe suficiente material denominado "tepetate" para satisfacer los requerimientos del sitio de disposición final; este material fue el producto del movimiento de tierras durante la construcción de la carretera federal (Figura 6) y que fue abandonado en este sitio.
Una vez seleccionado el sitio, se procedió a la toma de muestras inalteradas del estrato inferior (capa basal) de la ex-mina, con la finalidad de realizar los estudios de laboratorio; cabe mencionar que las muestras fueron recuperadas y tratadas adecuadamente para que éstas no perdieran sus características físicas (humedad, consistencia, porosidad, etc.) y que los análisis fueran confiables. Los resultados obtenidos se exponen a continuación:

Clasificación. La capa basal, de color café oscuro, que sería la base de las celdas de residuos sólidos, se clasificó como una arena arcillosa con contenido de finos de baja plasticidad y medianamente compacta.

Permeabilidad. Los análisis mostraron una permeabilidad "media a alta" con un valor de $\mathrm{K}=1.19 \times 10^{-9} \mathrm{~cm} /$ $\mathrm{s}$, por lo que se recomienda el uso de una geomembrana de $1.5 \mathrm{~mm}$ de espesor debido a que se estima una presión equivalente a la que imprime un espesor igual a $10 \mathrm{~m}$ de residuos sólidos. Si fuese menor a $10 \mathrm{~m}$ el espesor de residuos, la geomembrana podrá ser de $1 \mathrm{~mm}$ de espesor.

Deformación. En cuanto a la deformación, se establece que el sustrato es poco deformable debido a que se trata de un material competente, es decir, que por tratarse de un 
Tabla 7. Características de los sitios estudiados para construcción del relleno sanitario

\begin{tabular}{lcc}
\hline & \multicolumn{2}{c}{ Sitio } \\
& Los Duranes & Francisco Villa \\
\hline Latitud & $19^{\circ} 52.8$ & $19^{\circ} 52.6$ \\
Longitud & $100^{\circ} 54.8$ & $100^{\circ} 55.6$ \\
Capacidad de la estructura $\left(\mathrm{m}^{3}\right)$ & 157500 & 137149 \\
Distancia a aeropuerto & Si cumple & Si cumple \\
Áreas Naturales Protegidas & Si cumple & Si cumple \\
Distancia a la población más cercana & No cumple & Si cumple \\
Estabilidad del terreno & No cumple & Si cumple \\
Zonas de inundación o marismas & No cumple & Si cumple \\
Distancia a cuerpos de agua & Si cumple & Si cumple \\
Distancia a pozos de extracción & Si cumple & Si cumple \\
\hline
\end{tabular}

Fuente: Sánchez-Núñez et al., 2007. La información contenida en esta tabla fue elaborada con fundamento en la interpretación de las cartas editadas por el INEGI con clave "Zinapécuaro E14A14" de escala 1:50 000, topográfica, geológica y de uso de suelo, así como en los recorridos de verificación en campo. En la descripción de cada uno de los sitios evaluados se proporciona información detallada de otros criterios que fueron tomados en consideración para la selección final.

flujo piroclástico soldado (flujo de pómez), es un material susceptible a poca deformación debido a sus características físicas y su comportamiento mecánico.

Ensaye Triaxial. Se realizó en un material reproducido al 95\% de su Peso Volumétrico (PVSM), lo que indica que el material que se colocará como base del relleno sanitario (tepetate) debe llegar a esa compactación.

Capacidad de Carga. La capacidad de carga del sustrato se presenta con un valor mínimo de $10 \mathrm{ton} / \mathrm{m}^{2}$, lo que indica que el terreno no tiene riesgo a la deformación pues posee una estructura que le permite tener una alta capacidad de carga.

\subsection{Propuesta de diseño del relleno sanitario}

Con los resultados anteriores, se elaboró la proyección a 13 años de la población que podría ser beneficiada con el relleno sanitario. El modelo matemático seguido fue el de las poblaciones biológicas en expansión que asume una tasa de crecimiento geométrico (constante). La expresión no. 7 muestra su cálculo:

Donde:

$$
P_{f}=P_{0}(1+r)^{n}
$$

Pf $=$ Población futura

Po $=$ Población actual

$\mathrm{r}=$ Tasa de crecimiento

$\mathrm{n}$ = número de años a proyectar

La tasa de crecimiento poblacional para el municipio de Zinapécuaro según la COPLADE (2002) tiene un valor de $2 \%$ entre el año de 1990 y 1995 mientras que la población actual en la cabecera municipal es de 14,547 habitantes.
Sustituyendo valores en (7) se tiene:

$$
\begin{aligned}
P_{f}= & 14,547(1+0.02)^{13} \\
& P_{f}=18,818 \text { Hab. }
\end{aligned}
$$

Área y volumen del relleno sanitario.

Dado que la forma de la cantera seleccionada para la construcción del sitio de disposición final es regular (paralelepípedo), el área y el volumen se calcularon tomando la magnitud del segmento $\overline{A D}(74.7 \mathrm{~m})$ al igual que el segmento $\overline{B C}$ (Figura 9). El área y el volumen de este cuerpo geométrico se calculó utilizando fórmulas convencionales:

$$
\begin{aligned}
& A=B * H \\
& A=153 \mathrm{~m} * 11,429 \\
& A=11,429 \mathrm{~m}^{2} \\
& V=A * H^{\prime} \\
& A=\left(11,429 \mathrm{~m}^{2}\right)(12 \mathrm{~m}) \\
& A=137,149 \mathrm{~m}^{3}
\end{aligned}
$$

\section{Cálculo de la vida útil}

Para conocer la vida útil que tendrá el sitio seleccionado, se consideraron los siguientes factores: las dimensiones de la mina en desuso, el estudio de generación de residuos sólidos urbanos y la proyección de la población como se muestra en la Tabla 8. Como se observa, la vida útil del sitio es de 13 años y el volumen será de $133243.5 \mathrm{~m}^{3}$, es decir, el volumen de la estructura seleccionada.

Para el correcto diseño del sitio de disposición final de residuos sólidos, se deben tener en consideración los criterios anteriores, además de los factores mencionados por Jaramillo, 1999.

- Material de cobertura entre 20 - $25 \%$ del volumen total.

- Peso volumétrico de los residuos sólidos sueltos entre 200 y $300 \mathrm{~kg} / \mathrm{m}^{3}$

- Peso volumétrico de los residuos sólidos compactados entre 400 y $500 \mathrm{~kg} / \mathrm{m}^{3}$

- Factor de aumento de área adicional del $20-40 \%$ del área a rellenar.

Las bases de diseño que se utilizaron para el llenado de la Tabla 8 son las que a continuación se enlistan:

- Generación promedio de residuos de $0.62 \mathrm{~kg} / \mathrm{hab} /$ día.

- Población inicial de 14547 habitantes.

- Relación peso volumétrico suelto de $252.54 \mathrm{~kg} / \mathrm{m}^{3}$ (obtenido en el muestreo)

- Relación peso volumétrico suelto de $400 \mathrm{~kg} / \mathrm{m}^{3}$

- $20 \%$ anual de material de cobertura.

- Factor de aumento del área adicional del $30 \%$

Este último punto se considera por la construcción de vías de acceso, áreas de aislamiento, caseta de control, patio de maniobras e instalaciones sanitarias. 


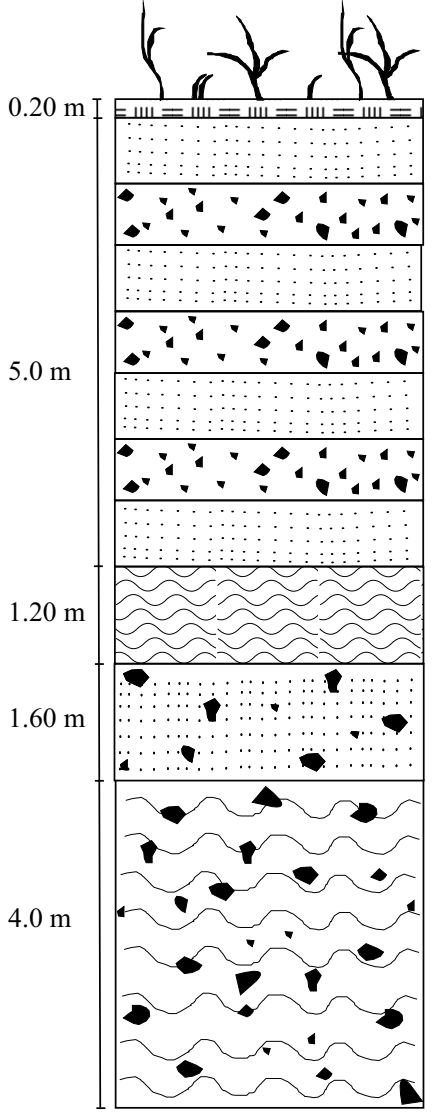

Capa de suelo con desarrollo incipiente de horizontes.

Alternancia de flujos piroclásticos de composición riolítica con horizontes de pómez de grano grueso (contacto grano a grano), con presencia de líticos accidentales de andesita.

Flujo de lodo con matriz de grano fino y abundante pómez.

Horizonte de flujo piroclástico poco consolidado, con matriz de grano fino y fragmentos de basalto.

Flujo de pómez de matriz fina con soldamiento (capa basal). Presenta fragmentos de pómez de $2 \mathrm{~mm}$ a $5 \mathrm{~cm}$, redondeados sin gradación.

Figura 7. Detalle de la secuencia ignimbrítica que aflora en la mina abandonada en estudio.
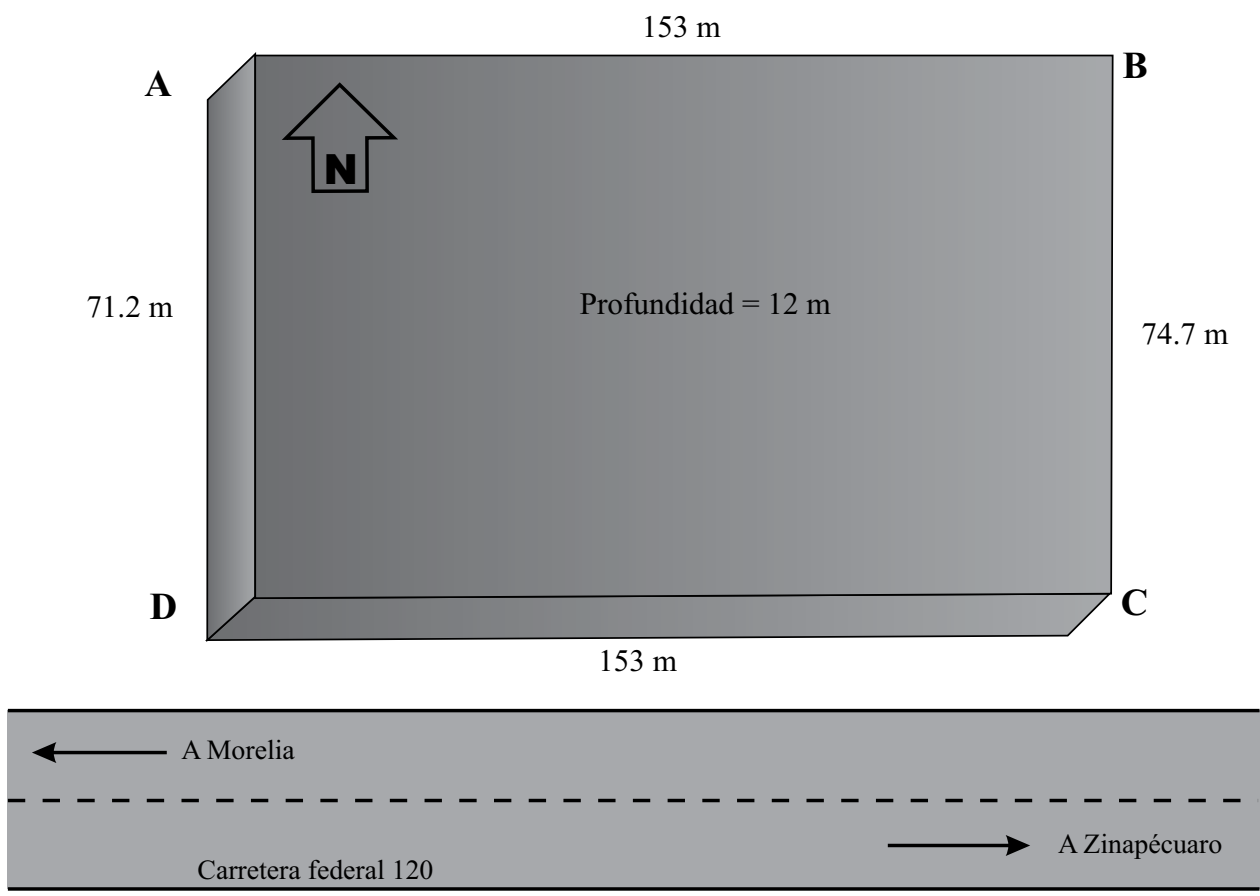

Fuente: Sánchez-Núñez et al., 2007

Figura 9. Esquema dimensional y de localización del sitio Francisco Villa, propuesto para construir el posible sitio de disposición final en Zinapécuaro, Michoacán. 


\section{Conclusiones}

Estadísticamente se comprobó que el muestreo realizado en la comunidad de Zinapécuaro fue aceptable, así como la generación per cápita de $0.626 \mathrm{~kg} / \mathrm{hab}$ día, valor que fue fundamental para definir el tipo y el diseño del sitio de disposición final. La generación calculada cae dentro del rango nacional para áreas rurales o bien para ciudades pequeñas. Con base en la cantidad de subproductos es factible la recuperación de vidrio, plástico (principalmente PET) y madera, para ser utilizados como materia prima en otros procesos, mientras que la fracción orgánica, por ser el residuo más abundante, puede ser tratada para elaborar composta y comercializarse entre la población que en gran medida se dedica a la agricultura. Las acciones anteriores permitirán que la vida útil del relleno sanitario se prolongue más de los 13 años proyectados.

Atendiendo los requerimientos marcados en la NOM083-SEMARNAT-2003, específicamente el criterio de la generación de residuos sólidos, el sitio de disposición final a desarrollar es de tipo "C", por tanto para este tipo de rellenos, no es obligatorio estimar la generación de biogás y lixiviados, sin embargo, resultaría conveniente realizar una estimación de estos dos componentes dado que pueden generar condiciones de peligro para la población o los mismos operadores del relleno.

De los dos sitios propuestos para la construcción del relleno sanitario, el ubicado cerca de la comunidad Francisco Villa cumplió con las especificaciones que marca la Norma Oficial Mexicana, destacando los criterios geológicos puesto que éstos marcan la pauta para la selección de cualquier sitio para confinar residuos, ya sean urbanos o con propiedades peligrosas. Por otro lado, resulta claro que en un estudio para el desplante de una obra de esta naturaleza es imprescindible que intervengan diferentes especialistas, todos ellos con el objetivo común de construir una obra civil que coadyuve a minimizar el impacto negativo de la disposición de residuos sólidos urbanos en tiraderos a cielo abierto, es por ello que en el desarrollo del presente estudio se cumplió con lo especificado por la normatividad ambiental vigente, además de incluir otros criterios que fueron fundamentales para la selección final.

En lo referente a la vulnerabilidad geológica-estratigráfica-estructural, se puede considerar como baja, en función de los argumentos expuestos hasta el momento, aunado a que la capa basal que soportará los residuos posee baja permeabilidad, alta cohesión y alta capacidad de carga, además de tener un espesor expuesto de $4.00 \mathrm{~m}$.

Finalmente, se debe resaltar que la presente propuesta se enfoca solamente a la selección del posible sitio de disposición final de RSU. Por otro lado, aunque la NOM083-SEMARNAT-2003 señala como obligatorio realizar los estudios para el tipo "C" de sitios de disposición final, resulta altamente recomendable realizar los estudios que se mencionan a continuación para confirmar o descartar el sitio seleccionado: Estudios de exploración indirectos (geofísicos) para conocer las estructuras y litología subterránea, estudios geohidrológicos de detalle para conocer la configuración del acuífero, dirección de flujo subterráneo y los actuales niveles freáticos; realizar pruebas de transmisividad para definir el grado de permeabilidad de los estratos que constituyen el acuífero, así como realizar análisis químicos del agua para determinar sus características físicas, químicas y biológicas.

\section{Agradecimientos}

A la Secretaría de Investigación y Posgrado del IPN, por el apoyo económico para realizar este proyecto con

Tabla 8. Cálculo de la vida útil del Relleno Sanitario

\begin{tabular}{|c|c|c|c|c|c|c|c|c|c|c|}
\hline \multirow[b]{2}{*}{$\begin{array}{l}\text { Tiempo } \\
\text { (años) }\end{array}$} & \multirow[b]{2}{*}{$\begin{array}{l}\text { Proyección } \\
\text { población }\end{array}$} & \multirow[b]{2}{*}{$\begin{array}{l}\text { Tasa de } \\
\text { aumento }\end{array}$} & \multicolumn{4}{|c|}{ Cantidad de Desechos } & \multicolumn{4}{|c|}{ Volumen de los residuos } \\
\hline & & & $\begin{array}{l}\text { Generación } \\
\text { (kg/hab/día) }\end{array}$ & $\begin{array}{l}\text { Generación } \\
\text { diaria (Ton) }\end{array}$ & $\begin{array}{l}\text { Generación } \\
\text { Anual (Ton) }\end{array}$ & $\begin{array}{l}\text { Desechos } \\
\text { acumulados } \\
\text { (Ton) }\end{array}$ & $\begin{array}{l}\text { Compactados } \\
\text { día } \mathrm{m}^{3}\end{array}$ & $\begin{array}{c}\text { Compactados } \\
\text { año }\end{array}$ & $\begin{array}{c}\text { Residuos } \\
\text { sólidos }+ \\
\text { MC* }^{*}\end{array}$ & $\begin{array}{c}\text { Volumen } \\
\text { acumulado } \\
\left(\mathrm{m}^{3}\right)\end{array}$ \\
\hline 1 & 14838 & 0.0062 & 0.6262 & 9.3 & 3391.4 & 3391.4 & 23.2 & 8478.5 & 8520.9 & 8520.9 \\
\hline 2 & 15135 & 0.006262 & 0.6325 & 9.6 & 3493.8 & 6885.2 & 23.9 & 8734.6 & 8778.2 & 17299.1 \\
\hline 3 & 15437 & 0.00632462 & 0.6388 & 9.9 & 3599.3 & 7093.2 & 24.7 & 8998.3 & 9043.3 & 26342.5 \\
\hline 4 & 15746 & 0.00638787 & 0.6452 & 10.2 & 3708.0 & 7307.4 & 25.4 & 9270.1 & 9316.4 & 35658.9 \\
\hline 5 & 16061 & 0.00645174 & 0.6516 & 10.5 & 3820.0 & 7528.1 & 26.2 & 9550.1 & 9597.8 & 45256.7 \\
\hline 6 & 16382 & 0.00651626 & 0.6581 & 10.8 & 3935.4 & 7755.4 & 27.0 & 9838.5 & 9887.7 & 55144.4 \\
\hline 7 & 16710 & 0.00658142 & 0.6647 & 11.1 & 4054.2 & 7989.6 & 27.8 & 10135.6 & 10186.3 & 65330.6 \\
\hline 8 & 17044 & 0.00664724 & 0.6714 & 11.4 & 4176.7 & 8230.9 & 28.6 & 10441.7 & 10493.9 & 75824.5 \\
\hline 9 & 17385 & 0.00671371 & 0.6781 & 11.8 & 4302.8 & 8479.5 & 29.5 & 10757.0 & 10810.8 & 86635.3 \\
\hline 10 & 17733 & 0.00678085 & 0.6849 & 12.1 & 4432.8 & 8735.6 & 30.4 & 11081.9 & 11137.3 & 97772.6 \\
\hline 11 & 18087 & 0.00684866 & 0.6917 & 12.5 & 4566.6 & 8999.4 & 31.3 & 11416.6 & 11473.6 & 109246.3 \\
\hline 12 & 18449 & 0.00691714 & 0.6986 & 12.9 & 4704.5 & 9271.2 & 32.2 & 11761.3 & 11820.1 & 121066.4 \\
\hline 13 & 18818 & 0.00698632 & 0.7056 & 13.3 & 4846.6 & 9551.1 & 33.2 & 12116.5 & 12177.1 & 133243.5 \\
\hline
\end{tabular}

Fuente: Sánchez-Núñez et al., 2007. *MC=Material de Cobertura 
no. SIP 20070206, a las autoridades del Municipio de Zinapécuaro por las facilidades otorgadas; a Carlos Martínez y Adrián Jiménez del SEGEOMET por su apoyo en el trabajo de campo y de manera muy especial en memoria del Dr. Armando García Palomo, quien fuera mi amigo, mi maestro y mi tutor.

\section{Referencias bibliográficas}

Acosta, A. 2001. Cambio en los patrones de consumo de agua y cambio de uso de suelo. El caso de la cuenca del lago de Cuitzeo (19752000). Tesis de Licenciatura, Universidad Michoacana de san Nicolás de Hidalgo. México. 142 pp

Arreygue-Rocha, E., Garduño-Monroy, V. H., Canuti, P., Casaglie, N., Lotti, A., Chiesa, S., 2001. Análisis geomecánico de la inestabilidad del escarpe La Paloma, en la Ciudad de Morelia, Michoacán, México. Revista Mexicana de Ciencias Geológicas. V. 1, num. 2. p 91-106

Brady, N. C. and Weil, R. R., 1996. The Nature and properties of soils. Prentice-Hall, Inc. New Jersey. 57-96

Buenrostro O. e Israde-Alcantara I., (2002). La Generación de Residuos Sólidos Municipales en la Cuenca del Lago de Cuitzeo, México. Ciencia Nicolaita. Vol.33: 71-84.

Buenrostro e Israde-Alcantara (2003) La Gestión de los Residuos Sólidos Municipales en la Cuenca de Cuitzeo, México. Revista Internacional de Contaminación Ambiental. Vol. 19 Num. 4: 161-169

Brunner, D. and Keller, D., 1972. Sanitary Landfill Design and Operation. U. S. Environmental Protection Agency. Report SW-65. 59 pp.

Carabias, J., Landa, R., Collado, J. y Martínez, P., 2005. Agua, Medio Ambiente y Sociedad. Hacia la gestión integral de los recursos hídricos en México. Universidad Nacional Autónoma de México, El Colegio de México y Fundación Gonzalo Río Arronte. 219 pp.

Cas, R.A.F. and Wright, J. V., 1988. Volcanic Successions. Modern and Ancient. Great Britain. Oxford University Press. 93-128

Castelán, J. E. 2000. Análisis y Perspectiva del Recurso Hídrico en México. Centro del Tercer Mundo para el Manejo del Agua, A. C. y el Centro Interdisciplinario de Investigaciones y Estudios sobre Medio Ambiente y Desarrollo-IPN. 98 pp

CNA, 2002. Comisión Nacional del Agua. Determinación de la disponibilidad de agua en el acuífero Ciénega Prieta-Moroleón, Estado de Guanajuato. Subdirección General Técnica, Gerencia de Aguas Subterráneas, Subgerencia de Evaluación y Modelación Hidrogeológica. $25 \mathrm{pp}$

CNA, 2004. Comisión Nacional del Agua. Estadísticas del Agua en México. Sistema Unificado de Información Básica del Agua (SUIBA). Segunda Edición. México. 143 pp

COPLADE, 2002. Comité de Planeación y Desarrollo Estatal del Gobierno del Estado de Michoacán, En Línea: http://www.michoacan.gob.mx/cgi-bin/htsearch. Consulta: 21/04/05.

CRM, 1995. Consejo de Recursos Minerales. Secretaria de Comercio y Fomento Industrial "monografía Geológico-Minera del Estado de Michoacán, México. $176 \mathrm{pp}$

Durán de la Fuente, Hernán. 1997. Gestión Ambientalmente Adecuada de Residuos Sólidos, un Enfoque de Política Integral. Comisión Económica para América Latina y el Caribe de las Naciones Unidas (CEPAL) y Cooperación Técnica Alemana (GTZ), $20 \mathrm{p}$

Ferrari, L., Garduño, V.H., Pasquare, G., Tibaldi, A., 1994, Volcanic and tectonic evolution of Central Mexico, Oligocen to Present: Geofisica Internacional, 33, 91-105.

Flores-Flores, M., 2005. Degradación del recurso hídrico provocado por el tiradero a cielo abierto, ubicado en Zinapécuaro, Michoacán. Tesis profesional. ENCB-ISA. $52 \mathrm{pp}$

Garduño-Monroy, V.H., Arreygue-Rocha, E., Israde-Alcántara, I., Rodríguez-Torres, G.M., 2001, Efectos de las fallas asociadas a sobreexplotación de acuíferos y la presencia de fallas potencialmente sísmicas en Morelia, Michoacán, México: Revista Mexicana de Ciencias Geológicas, 18 (1), 37-54.
García, M. E., 1973. Modificaciones al sistema de clasificación de Köpen. Segunda edición. Instituto de Geografía. UNAM. 243 p.

González, R. C., 2003. La producción de residuos peligrosos en los residuos urbanos de seis municipios de la cuenca de Cuitzeo. Tesis profesional. Facultad de Biología. UMSNH.

Hans-Ulrich, Schmincke,. 2004. Volcanism. Springer-Verlang, Berlin Heidelberg. 93-128

Hasenaka, T., y Carmichael, I.S.E., 1985, The cinder cones of MichoacánGuanajuato, Central, Mexico-their age, volume and distribution, and magma discharge rate: Journal of Volcanology and Geothermal Research, v. 25, núms. 1-2, p. 105-124.

Henry J. G. y Heinke G.W. 1999. Ingeniería Ambiental $2^{\circ}$ Ed. Prentice Hall Pearson. México 761pp

INE-SEMARNAT, 2001. Minimización y Manejo Ambiental de los Residuos Sólidos. Instituto Nacional de Ecología, Secretaría del Medio Ambiente y Recursos Naturales. Secretaría de Gobernación. $235 \mathrm{pp}$

INEGI, 2000. Instituto Nacional de Estadística Geografía e Informática. XII Censo General de Población y Vivienda. Datos finales.

INEGI, 2002. Instituto Nacional de Estadística Geografía e Informática. Carta Geológica. Escala 1: 50,000. Segunda impresión. Zinapécuaro, Michoacán. Clave E14 A 14.

INEGI, 2002a. Instituto Nacional de Geografía e Informática. Estadísticas del Medio Ambiente Tomo I. 359 pp

Israde- Alcántara I., Buenrostro-Delgado, O., Carrillo-Chávez, A., 2005. Geological characterization and environmental implication of the placement of the Morelia dump, Michoacán, central Mexico. Journal of the air and waste management association. Vol. 55, Issue 6 (june), pp. 755-764

Israde-Alcántara, I., Garduño-Monroy, V.H. y Ferrari, M., 1992. El origen transtensivo de la depresión del lago de Cuitzeo, México, en VIII Congreso Latinoamericano de Geología, Actas de las sesiones científicas; Salamanca, España, v. 4, p.127-131.

Israde-Alcántara, I., Garduño-Monroy, V.H., Ibáñez-Garduño, D., Alatorre,M. A., Carrillo-Chávez, IA., Rizzi, Agostino, Soto, L. 2004. Caracterización geológico ambiental del tiradero de Morelia y su relación con las poblaciones del entorno. En: Contribuciones a la geología e impacto ambiental de la región de Morelia. UMSNH. Instituto de Investigaciones Metalúrgicas, Morelia, Michoacán. México. p 137-155

Israde-Alcántara, I., Garduño-Monroy, V.H., 1999. Lacustrine record in a volcanic intra-arc setting. The evolution of the Late Neogene Cuitzeo basin system (central western Michoacan, Mexico): Palaecogeography, Palaoclimatology, Palaecology, 15 (1-3), 209-227.

Jaramillo J. 1999. Guía para el diseño construcción y operación de rellenos sanitarios manuales, OMS, OPS, Secretaria de Salud. México.147 pp

López, R. E. 1983. Geología de México. Tercera Edición.453 pp

NMX-AA-015-1985. Norma Técnica sobre el Método de cuarteo de los RSU. Gestión Ambiental Mexicana. En: Cultura Ecológica, CD Versión 16, 2005

NMX-AA-019-1985. Peso volumétrico in situ de los RSU. Gestión Ambiental Mexicana. En: Cultura Ecológica, CD Versión 16, 2005.

NMX-AA-022-1985. Selección y cuantificación de subproductos. Gestión Ambiental Mexicana. En: Cultura Ecológica, CD Versión $16,2005$.

NMX-AA-061-1985. Determinación de la generación de los RSU. Gestión Ambiental Mexicana. En: Cultura Ecológica, CD Versión 16, 2005.

NOM-083-SEMARNAT-2003. Especificaciones de protección ambiental para la selección del sitio, diseño, construcción, operación, monitoreo, clausura y obras complementarias de un sitio de disposición final de residuos sólidos urbanos y de manejo especial. Gestión Ambiental Mexicana. En: Cultura Ecológica, CD Versión 16, 2005.

Orta, V. 2004 "Estudios básicos para la instalación de un relleno sanitario manual en el municipio de Santo Tomas Jalieza, Oaxaca" Tesis profesional, ENCB - IPN, México. 
Pompa I. 1995. "Impacto del Deterioro Ambiental del Lago de Cuitzeo en organizaciones de pescadores de la ribera" Tesis profesional, Universidad Autónoma de Chapingo, México.

Pradal, E. \& Robin, C., 2005. Late Pleistocene ignimbrites at Los Azufres volcanic centre, Mexico. Implications for the present magmatic cycle. Geodynamique 6(2). pp 201-205

Robles, M. F., 2005. Generación de biogás y lixiviados en los rellenos sanitarios. Dirección General de Publicaciones del IPN. pp 65-88

Santiago-Hipólito, I., 2005. Estudio de la contaminación por metales pesados de lixiviados en la zona del tiradero municipal de Zinapécuaro, Michoacán, México. Tesis profesional, Facultad de Biología, UMSNH. pp 78

Sánchez-Núñez, J. M., Serrano, F., Ramírez, T., Betanzos, A. y Flores, F., 2007. Diagnóstico de las afectaciones al recurso hídrico provocadas por el tiradero a cielo abierto en Zinapécuaro, Mich. Informe Final del proyecto SIP 20070207 IPN.

Seoánez M. 1993. "Residuos, Problemática, descripción, manejo, aprovechamiento y destrucción" 2a Edición. Ediciones Mundi Prensa España 486 pp
Tchobanoglous G. 1998. "Gestión Integral de Residuos Sólidos" $2^{\circ}$ Edición, Tomo I. Editorial Mc Graw - Hill. 607 pp

Ulrico, Schmincke. 2004. Volcanism. Springer-Verlang, Berlin Heidelberg. 93-128

Vargas, U. G. 2000. Apuntes e indicadores para la historia ambiental regional de Michoacán. Centro de Investigaciones Económicas y Sociales, Escuela de Economía/Facultad de Biología. Universidad Michoacana de San Nicolás de Hidalgo. Morelia, Michoacán, México. $327 \mathrm{pp}$

Manuscrito recibido: Octubre 2, 2007

Manuscrito corregido recibido: Mayo 16, 2008

Manuscrito aceptado: Junio 2, 2008 